Article

\title{
Reaction of Stabilized Criegee Intermediates from Ozonolysis of Limonene with Water: $A b$ Initio and DFT Study
}

\author{
Lei Jiang ${ }^{1,2}$, Ru Lan ${ }^{3}$, Yi-Sheng Xu ${ }^{1, *}$, Wen-Jie Zhang ${ }^{1}$ and Wen Yang ${ }^{1}$
}

1 State Key Laboratory of Environmental Criteria and Risk Assessment, Chinese Research Academy of Environmental Sciences, Beijing 100012, China; E-Mails: jiangle3657@sina.com (L.J.); zhangwj@craes.org.cn (W.-J.Z.); yangwen@craes.org.cn (W.Y.)

2 College of Environmental Sciences and Engineering, Peking University, Beijing 100871, China

3 China Waterborne Transport Research Institute, Beijing 100088, China; E-Mail: lanru@wti.ac.cn

* Author to whom correspondence should be addressed; E-Mail: xuys@craes.org.cn; Tel.: +86-10-8491-5249; Fax: +86-10-8491-5248.

Received: 5 January 2013; in revised form: 7 February 2013 / Accepted: 4 March 2013 /

Published: 12 March 2013

\begin{abstract}
The mechanism of the chemical reaction of $\mathrm{H}_{2} \mathrm{O}$ with three stabilized Criegee intermediates (stabCI-OO, stabCI-CH$H_{3}-\mathrm{OO}$ and stabCI $x$-OO) produced via the limonene ozonolysis reaction has been investigated using $a b$ initio and DFT (Density Functional Theory) methods. It has been shown that the formation of the hydrogen-bonded complexes is followed by two different reaction pathways, leading to the formation of either $\mathrm{OH}$ radicals via water-catalyzed $\mathrm{H}$ migration or of $\alpha$-hydroxy hydroperoxide. Both pathways were found to be essential sources of atmospheric $\mathrm{OH}$ radical and $\mathrm{H}_{2} \mathrm{O}_{2}$ making a significant contribution to the formation of secondary aerosols in the Earth's atmosphere. The activation energies at the $\operatorname{CCSD}(\mathrm{T}) / 6-31 \mathrm{G}(\mathrm{d})+\mathrm{CF}$ level of theory were found to be in the range of $14.70-21.98 \mathrm{kcal} \mathrm{mol}^{-1}$. The formation of $\alpha$-hydroxy hydroperoxide for the reaction of stabCI $x$-OO and $\mathrm{H}_{2} \mathrm{O}$ with the activation energy of $14.70 \mathrm{kcal} \mathrm{mol}^{-1}$ is identified as the most favorable pathway.
\end{abstract}

Keywords: volatile organic chemicals (VOCs); ozone; ab initio methods; ozonolysis reaction mechanisms; limonene 


\section{Introduction}

The stabilized Criegee intermediates (stabilized carbonyl oxides) from the ozonolysis of alkenes can react with various atmospheric compounds [1-5], particularly with the formaldehyde, $\mathrm{H}_{2} \mathrm{O}, \mathrm{NO}_{x}, \mathrm{SO}_{2}$, $\mathrm{H}_{2} \mathrm{SO}_{4}$ and $\mathrm{CO}$ and many others. One of the most important reactions in the atmospheric chemistry is the reaction of stabilized Criegee intermediates with water, the dominant constituent of condensable vapors in the Earth's atmosphere. This reaction is considered to be one of the major degradation reactions in the Earth's atmosphere [6,7]. It is also known that this reaction leads to the formation of $\alpha$-hydroxy hydroperoxides $\left(\mathrm{HOCH}_{2} \mathrm{OOH}\right.$ or $\left.\mathrm{HMHP}\right)$, organic acids, ketones, aldehydes, $\mathrm{OH}$ radicals, and $\mathrm{H}_{2} \mathrm{O}_{2}$ [6,8-19]. These species have been detected in both the ambient air and precipitation, in both forested and urban areas under polluted conditions [15,20-25]. HMHP may act as an enzymatic inhibitor of peroxidases, while $\mathrm{H}_{2} \mathrm{O}_{2}$ is a very important oxidant [26-28]. The $\mathrm{H}_{2} \mathrm{O}_{2}$ contributes to acid precipitation via the conversion of $\mathrm{SO}_{2}$ into $\mathrm{H}_{2} \mathrm{SO}_{4}$ [29], which is the key atmospheric nucleation precursor. The reaction of stabilized Criegee intermediate with water can be an additional essential source of $\mathrm{OH}$ radicals [30]. The oxidation of $\mathrm{H}_{2} \mathrm{O}$ by stabilized Criegee intermediates in ozonolysis of alkenes can also contribute to the formation of secondary organic aerosol (SOA) [31,32]. Jonsson et al. [31] corroborated the aforementioned conclusion for the ozonolysis of limonene, $\Delta^{3}$-carene, and $\alpha$-pinene at low concentrations of the aforementioned species and noticed that the particle number and mass concentration increases with increasing relative humidity The reaction of stabilized Criegee intermediate with water is also important for the water purification and waste water processes, where ozonolysis is widely used [33].

Previous experimental and theoretical studies on the reaction of $\mathrm{H}_{2} \mathrm{O}$ with $\mathrm{CH}_{2} \mathrm{OO}$ and $\mathrm{CH}_{3} \mathrm{HCOO}$, $\left(\mathrm{CH}_{3}\right)_{2} \mathrm{COO}$ and the stabilized Criegee intermediate from ozonolysis of limonene indicate that this reaction is the three-step mechanism [2,6,34-38]. At the first step, a hydrogen-bond complex is formed (a). At the second step, two decomposition pathways for the hydrogen-bond complex are possible: water-catalyzed hydrogen $(\mathrm{H})$ migration would lead to the formation of $\mathrm{OH}$ radical via $\mathrm{OO}$ bond breaking (b). At the final stage, the $\alpha$-hydroxy hydroperoxide is formed by the addition of the water molecule to the stabilized Criegee intermediate. Sauer et al. [14] found that $\alpha$-hydroxy hydroperoxides $\mathrm{RR}^{\prime} \mathrm{C}(\mathrm{OH}) \mathrm{OOH}$ formed in the reaction of the stabilized Criegee intermediate and water may have different fates depending on the chemical nature of the $\mathrm{R}$ and $\mathrm{R}^{\prime}$ substitutes (see Scheme 1).

Being produced by more than 300 species, limonene or 4-isopropenyl-1-methyl-cyclohexene, is the most abundant monoterpene in the Earth's troposphere [39,40]. The reaction of ozone with limonene, which has both endocyclic and exocyclic double bonds, is one of the most important oxidation processes in the Earth's troposphere. Ozonolysis of limonene is an essential source of $\mathrm{OH}$ radicals, $\mathrm{H}_{2} \mathrm{O}_{2}$ and plays a significant role in the formation of atmospheric aerosols via the oxidation of $\mathrm{H}_{2} \mathrm{O}$ by stabilized Criegee intermediate [31]. There are four stabilized Criegee intermediate formed from cleavage of the $\mathrm{O}_{3}$-Limonene primary ozonide: stabCI-OO (See stabCI-OO structure in Figure 1) and stabCI- $\mathrm{CH}_{3}$-OO (See stabCI- $\mathrm{CH}_{3}-\mathrm{OO}$ structure in Figure 2) formed from the endocyclic primary ozonide decomposition and stabCI $x$-OO (See stabCI $x-\mathrm{OO}$ structure in Figure 3 ) and $\mathrm{stabCH}_{2} \mathrm{OO}$ formed from the exocyclic primary ozonide decomposition [41]. 
Scheme 1. Different fates of RR'C $(\mathrm{OH}) \mathrm{OOH}$ formed in the reaction of the stabilized Criegee intermediate and water depending on the chemical nature of the $\mathrm{R}$ and R' substitutes.

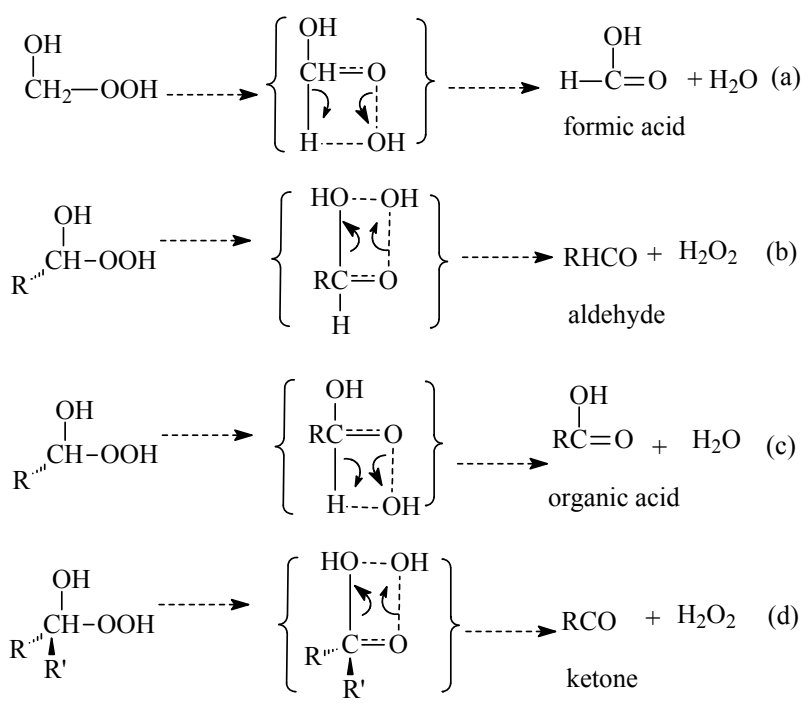

The mechanistic diagrams for the reactions of $\mathrm{H}_{2} \mathrm{O}$ with three stabilized Criegee intermediates (stabCI-OO, stabCI-CH $H_{3}-\mathrm{OO}$ and stabCI $x$-OO) from ozonolysis of limonene are shown in Schemes 2-4, respectively. The structures of the intermediate adduct and transition states are denoted as $\mathrm{M}$ and TS, respectively. The H1_S, H2_S and H3_S are used to distinguish the reactions of $\mathrm{H}_{2} \mathrm{O}$ with stabCI-OO, stabCI- $\mathrm{CH}_{3}-\mathrm{OO}$ and stabCI $x$-OO. The reactions of $\mathrm{H}_{2} \mathrm{O}$ with all the three stabilized Criegee intermediates are three-step reactions. For each reaction, a hydrogen-bond complex is initially formed. The further evolution of the hydrogen-bond complex formed occurs via two different reaction pathways:

(1) Formation of $\mathrm{OH}$ radicals with water-catalyzed $\mathrm{H}$ migration. The water molecule assists the $\mathrm{H}$ migration toward the terminal oxygen of the COO moiety, which could lead to the formation of $\mathrm{OH}$ radicals.

(2) Formation of $\alpha$-hydroxy hydroperoxide. Cycloaddition of $\mathrm{H}_{2} \mathrm{O}$ to stabilized Criegee intermediate, where the oxygen of water is linked to the carbon atom of the stabilized Criegee intermediate while a hydrogen atom of water is transferred to the terminal oxygen of the $\mathrm{COO}$ unit.

The reaction pathway (2) have different fates depending on the nature of the R and R' substitutes in subsequent reactions. For reaction between stabCl-OO and $\mathrm{H}_{2} \mathrm{O}$, the M1H1_S (hydrogen-bond complex) is getting transformed via the two main reaction pathways (pathway (1) and pathway (2)) through the corresponding transition states (TSM11H1_S and TSM12H1_S), producing M2H1_S and M3H1_S, respectively. In pathway (1), M2H1_S evolves via losing water molecule and the transition state (TSM4H1_S), to produce $\mathrm{OH}$ and R1H1_S radicals (pathway (aH1_S)). M3H1_S in pathway (2) may have different degradation paths. $\mathrm{M} 3 \mathrm{H} 1$ _S can be transformed via the transition state (TSM31H1_S) into $\mathrm{OH}$ and $\mathrm{R} 2 \mathrm{H} 1 \_\mathrm{S}$ radicals (pathway (b1H1_S)), limononic acid and $\mathrm{H}_{2} \mathrm{O}$ (pathway (b2H1_S-b5H1_S)) and limononaldehyde and $\mathrm{H}_{2} \mathrm{O}_{2}$ (via the transition states (TSM32H1_S-TSM35H1_S) (pathway (b6H1_S)). Moreover, the pathway (b4H1_S) was also found for the reaction between $\mathrm{H}_{2} \mathrm{O}$ and stabCl-OO in the recent study of Wang [42]. 
Scheme 2. Mechanistic diagram for the reaction between $\mathrm{H}_{2} \mathrm{O}$ and stabCI-OO arising from the limonene ozonolysis.

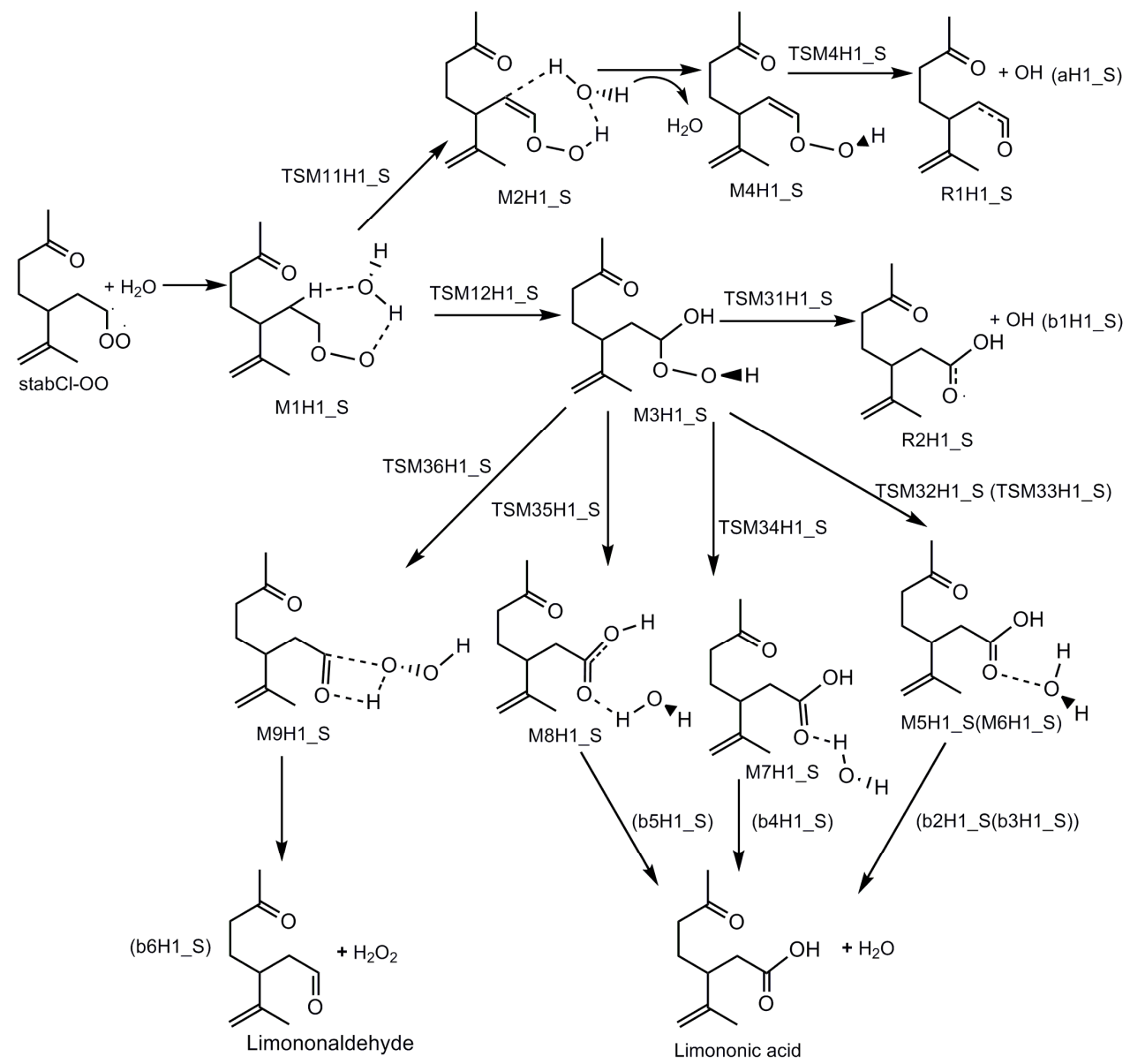

Scheme 3. Mechanistic diagram for the reaction between $\mathrm{H}_{2} \mathrm{O}$ and stabCI- $\mathrm{CH}_{3}-\mathrm{OO}$ arising from the limonene ozonolysis.

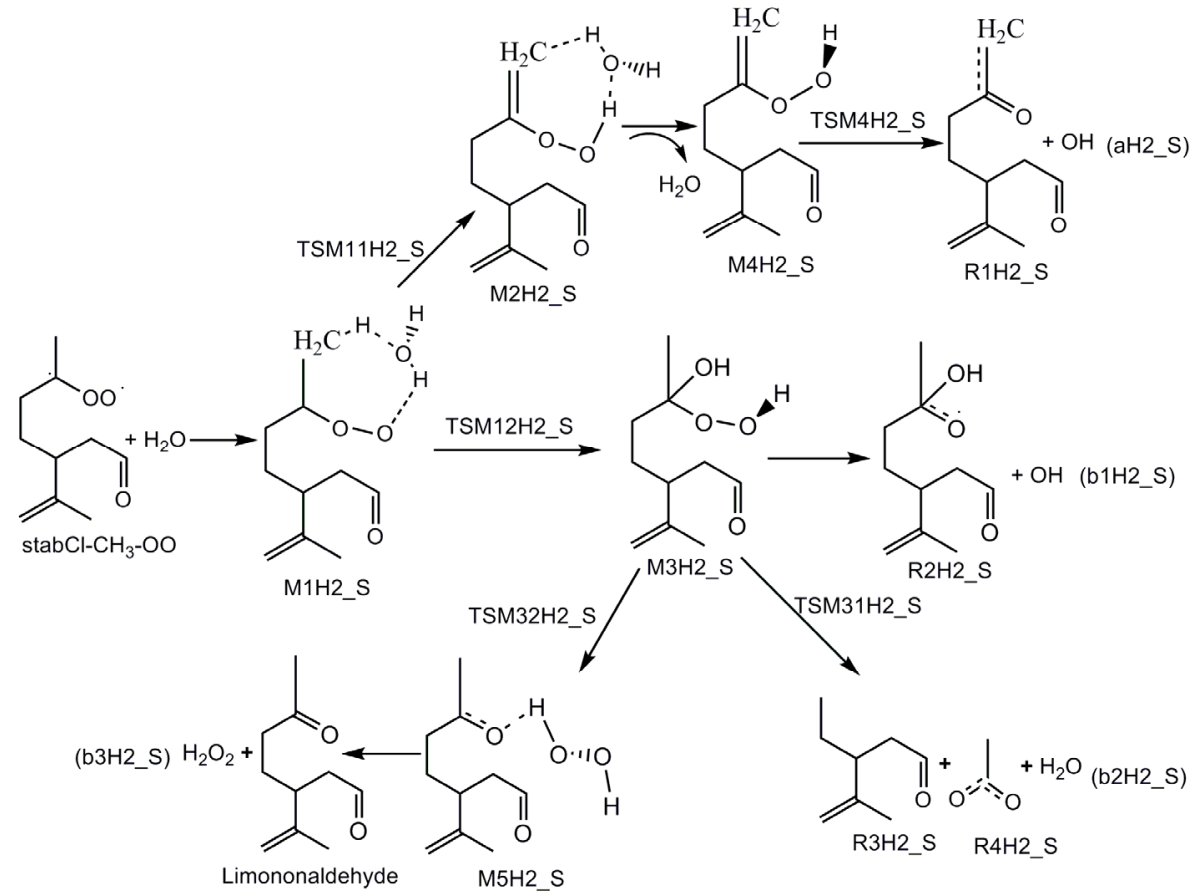


Scheme 4. Mechanistic diagram for the reaction between $\mathrm{H}_{2} \mathrm{O}$ and stabCIx-OO arising from the limonene ozonolysis.

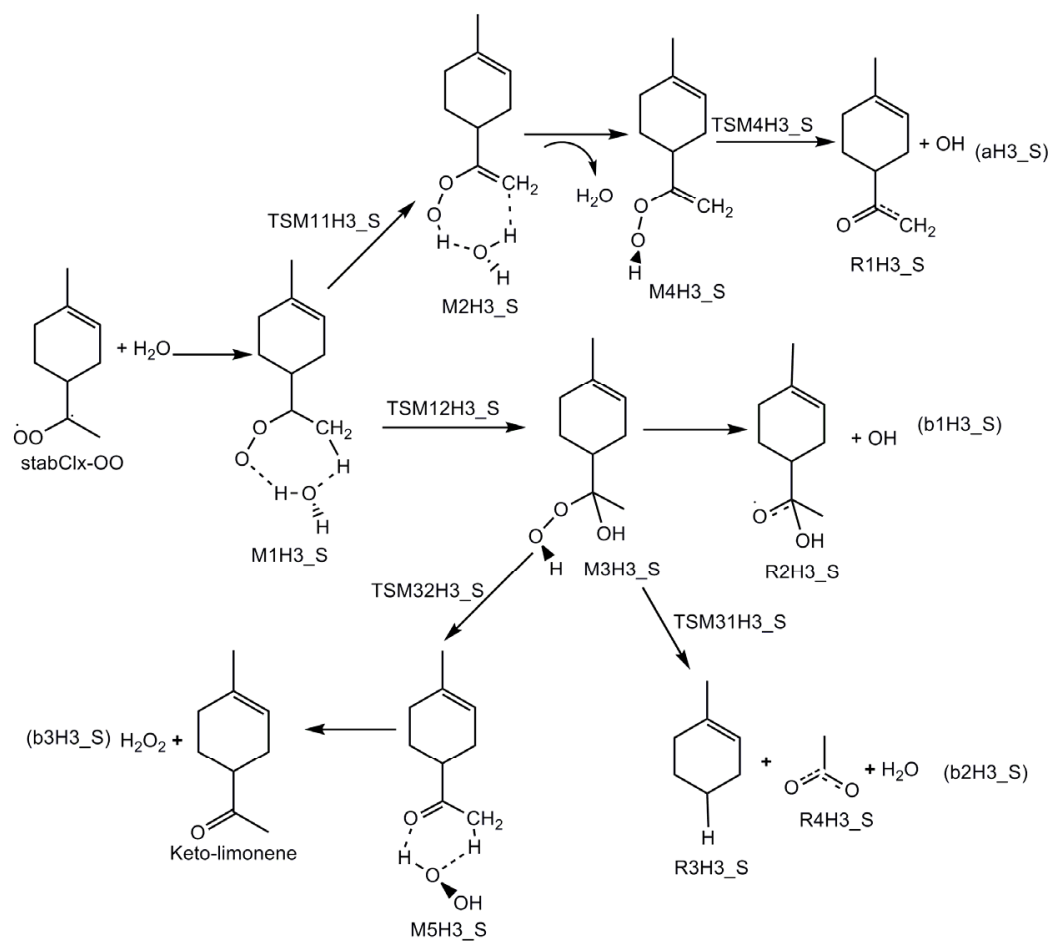

In the reaction between stabCI- $\mathrm{CH}_{3}-\mathrm{OO}$ and $\mathrm{H}_{2} \mathrm{O}$, the hydrogen-bonded complex $\mathrm{M} 1 \mathrm{H} 2$ _S evolves via their corresponding transition states (TSM11H2_S and TSM12H2_S), leading to the formation of M2H2_S and M3H2_S, respectively. In pathway (1), M2H2_S evolves via the detachment of the water molecule and the transition state (TSM4H2_S), to produce $\mathrm{OH}$ and R1H2_S radicals (pathway $(\mathrm{aH} 2$ _S )). M3H2_S may follow three different reaction pathways in pathway (2). M3H2_S can be transformed into $\mathrm{OH}$ and $\mathrm{R} 2 \mathrm{H} 2{ }_{-} \mathrm{S}$ radicals (pathway $\left(\mathrm{b} 1 \mathrm{H} 2 \_\mathrm{S}\right.$ )) or via the transition states (TSM31H2_S and TSM32H2_S), into $\mathrm{H}_{2} \mathrm{O}, \mathrm{R} 3 \mathrm{H} 2$ _S, R4H2_S, limononaldehyde and $\mathrm{H}_{2} \mathrm{O}_{2}$. The reaction between stabCI $x$-OO and $\mathrm{H}_{2} \mathrm{O}$ follows the same pathways as those for the reaction of stabCI- $\mathrm{CH}_{3}-\mathrm{OO}$ and $\mathrm{H}_{2} \mathrm{O}$. The $\mathrm{M} 1 \mathrm{H} 3$ _S can evolve via their corresponding transition states (TSM11H3_S and TSM12H3_S) to formation of OH radical, R1H3_S radical, R2H3_S radical, R3H3_S, R4H3_S, $\mathrm{H}_{2} \mathrm{O}$, Keto-limonene and $\mathrm{H}_{2} \mathrm{O}_{2}$.

The formations of limononic acid, limononaldehyde and keto-limonene are consistent with the experimental results for the reaction between three stabilized Criegee intermediates and $\mathrm{H}_{2} \mathrm{O}$ in Limonene-ozone reaction in UNC smog chamber [32,43].

Although the important role of the reaction between Criegee intermediates from ozonolysis of limonene and $\mathrm{H}_{2} \mathrm{O}$ for the formation of SOA and organic acids affecting both the global climate changes and public health is well established, the mechanism of these reactions remains poorly understood. Since the stability of the Criegee intermediates is moderately weak, the computational quantum chemistry is the most efficient for determining the geometric and electronic structures of these chemically activated complexes. Since reaction between the simple stabC $\mathrm{H}_{2} \mathrm{OO}$ and $\mathrm{H}_{2} \mathrm{O}$ has been investigated in some detail $[6,11,44-51]$ in the past, the mechanism of this reaction is left out of the scope of the present paper. 
In the present paper, the reaction of $\mathrm{H}_{2} \mathrm{O}$ with three more complex stabilized Criegee intermediates (stabCI-OO, stabCI-CH $\mathrm{CH}_{3}-\mathrm{OO}$ and stabCI $x$-OO) from ozonolysis of limonene has been investigated in order to gain new insights of the oxidation mechanisms under atmospheric conditions. Ab initio and DFT methods have been employed to obtain geometries and energies of the transition states and subsequent degradation products. Reaction and activation energies for the reaction between the three stabilized Criegee intermediates and $\mathrm{H}_{2} \mathrm{O}$ have been computed at different levels of theory, including the higher level CCSD(T)/6-31G(d) + CF. A thorough thermochemical analysis has been carried out and its results and implications for the ozonolysis of limonene have been discussed.

\section{Computational Details}

The computations were performed using GAUSSIAN 03 suite of programs [52] on the SGI ALTIX 4700 supercomputer. The geometry optimization of all reactants, stabilized Criegee intermediates, transition states, and products was executed using Becke's three-parameter hybrid method employing the LYP correction function (B3LYP) with the split valence polarized basis set 6-31G(d,p) $[10,53]$. The stationary points were classified as minima in the case, when no imaginary frequencies were found, and as a transition state in the case, when only one imaginary frequency was obtained. In order to verify the transition states connecting reactants and products, the intrinsic reaction coordinate (IRC) analysis [54] at the B3LYP/6-31G(d,p) level of theory has also been applied to each transition state of every reaction. We just freely optimized the original three CI structure to get the minima conformer, then keeping the conformer for the succedent reactions. (see Figures 1-3). There exists difference between our optimized conformation and those in other studies. For example, in our study, we have chosen opposite orientation on stabCI-OO and stabCI $x$-OO from what Baptista et al. did [55]. In general, we think our method of computational process is applicable for explanation of unanimous reaction between the same conformer of CI with water. The DFT structures were then used in the single-point energy calculations using frozen core second-order Møller-Plesset perturbation theory (MP2) and coupled-cluster theory with single and double excitations including perturbative corrections for the triple excitations $(\mathrm{CCSD}(\mathrm{T})$ [56] with various basis sets. The basis set effects on calculated energies for the reactions of stabilized Criegee intermediates with $\mathrm{H}_{2} \mathrm{O}$ were corrected at MP2 level according to the developed method, which has been successfully applied for studying the complex reaction mechanisms and pathways of volatile organic compounds (VOCs) in the atmosphere [57]. A correction factor (CF) has been determined from the energy difference between the MP2/6-31G(d) and $\mathrm{MP} 2 / 6-311++\mathrm{G}(\mathrm{d}, \mathrm{p})$ levels. Energies calculated at the $\operatorname{CCSD}(\mathrm{T}) / 6-31 \mathrm{G}(\mathrm{d})$ level of theory have been corrected using the aforementioned MP2 level corrections. The application of the CF has been validated in several studies of isoprene and limonene reactions initiated by $\mathrm{NO}_{3}, \mathrm{OH}$ and $\mathrm{O}_{3}$ [57-61]. For example, new important results have been obtained using the same method for the reaction of stabilized Criegee intermediates from the ozonolysis of limonene with sulfur dioxide in the recent paper [41]. These considerations lead us to conclude that the CCSD(T)/6-31G(d) + CF selected as a primary method and calculation scheme are appropriate for studying the reactions of VOCs with ozone or $\mathrm{OH}$ radical and description of the Criegee intermediates in the ozonolysis of VOCs reaction $[35,37,47,62-66]$. 
Figure 1. Geometries of the stationary points in the stabCI-OO $+\mathrm{H}_{2} \mathrm{O}$ reaction obtained at the B3LYP/6-31G(d,p) level of theory. Bond lengths and intermolecular distances are given in $\AA$.
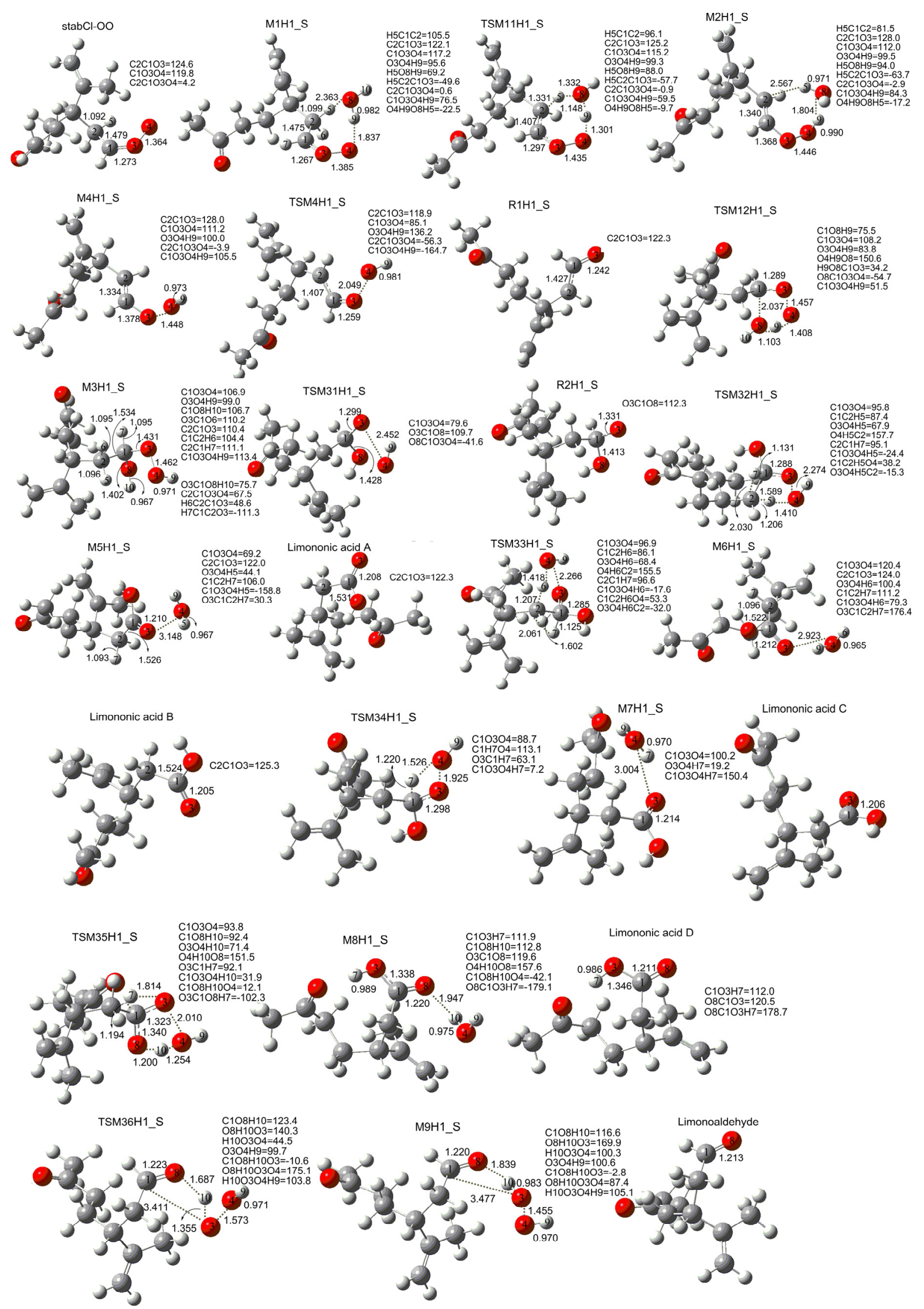


\section{Results and Discussion}

\subsection{Reaction Mechanism}

The reactions of $\mathrm{H}_{2} \mathrm{O}$ and limonene stabilized Criegee intermediates (stabCI-OO, stabCI-CH$-\mathrm{OO}$ and stabCI $x$-OO) occur via the six main reaction pathways. Each transition state has only one imaginary harmonic vibrational frequency and can be classified as the first-order saddle point. The values of imaginary frequencies for TSM11H1_S, TSM12H1_S, TSM11H2_S, TSM12H2_S, TSM11H3_S and TSM12H3_S transition states are 1516.76i, 434.95i, 1584.16i, 590.54i, 1586.31i and $593.62 \mathrm{i}$, respectively.

Figure 1 presents the optimized geometries of the stationary points for the reaction of stabCI-OO and $\mathrm{H}_{2} \mathrm{O}$ obtained at the $\mathrm{B} 3 \mathrm{LYP} / 6-31 \mathrm{G}(\mathrm{d}, \mathrm{p})$ level of theory and the most important corresponding geometrical properties such as bond lengths and bond angles. Scheme 2 and Figure 1 show that the reactions of stabCI-OO with $\mathrm{H}_{2} \mathrm{O}$ initially lead to the formation of the hydrogen-bond complex M1H1_S. Then the M1H1_S evolves via the transition state TSM11H1_S (formation of OH radicals with water-catalyzed $\mathrm{H}$ migration path or reaction (1)), to the hydrogen-bond complex M2H1_S, which can evolve into hydroperoxide M4H1_S and water. Finally, the cleavage of the O-OH bond in M4H1_S may lead to $\mathrm{OH}$ and R1H1_S radicals via the transition state TSM4H1_S along the reaction path (aH1_s).

As seen from Figure 1, there are some major changes in main bonds. In particular, the hydrogen-bond M1H1_S complex includes a seven-membered ring. The distance between O4 and H9 connecting the terminal oxygen atom $(\mathrm{O} 4)$ of the $\mathrm{C} 1 \mathrm{O} 3 \mathrm{O} 4$ group belonging to stabCI-OO to the hydrogen atom (H9), is $1.837 \AA$, while the length of the O8-H9 bond is $0.982 \AA$. The length of H5-O8 bond, which connects the oxygen (O8) of original water to the hydrogen atom (H5), is $2.363 \AA$. The corresponding transition (TSM11H1_S) shows that the transfer of the hydrogen atom (H5) linked to the carbon atom $(\mathrm{C} 2)$ to the water molecule can take place, and the transfer of one hydrogen atom (H9) from water to the terminal oxygen of the $\mathrm{C} 1 \mathrm{O} 3 \mathrm{O} 4$ group can also occur at the same time. This indicates that the water molecule acts as a catalyst of the hydrogen migration. A comparison of the corresponding transition (TSM11H1_S) structure with M1H1_S shows that the C2-H5 bond length increases by $0.232 \AA$ to $1.331 \AA$, while the H5-O8 distance decreases by $1.031 \AA$ to $1.332 \AA$. The O8-H9 bond length increases by $0.166 \AA$ to $1.148 \AA$, while the O4-H9 bond length decreases by 0.536 $\AA$ to $1.301 \AA$. C2-H5 and O8-H9 distances in TSM11H1_S continue to increase, leading to both $\mathrm{C} 2-\mathrm{H} 5$ and $\mathrm{O} 8-\mathrm{H} 9$ bonds broken and the formation of O8-H5 and O4-H9 bonds. At the same time, the hydrogen-bond complex M2H1_S is formed. The lengths of C2-H5, H5-O8, O8-H9 and O4-H9 bonds in M2H1_S are $2.567 \AA, 0.971 \AA, 1.804 \AA, 0.990 \AA$ and $1.446 \AA$, respectively. A hydroperoxide M4H1_S and water are formed from the M2H1_S. The O3-O4 and O4-H9 bonds in M4H1_S experiencing minor changes during this process are of $1.448 \AA$ and $0.973 \AA$, respectively. Finally, the $\mathrm{O}-\mathrm{OH}$ bond in M4H1_S is broken to form of O4H9 and R1H1_S radicals via the TSM4H1_S transition state. The O3-O4 bond in the peroxide (2.049 $\AA$ ) in TSM4H1_S complex gets elongated by $0.601 \AA$ compared to that in the M4H1_S. The reaction (1) may be considered as a possible significant source of atmospheric $\mathrm{OH}$ radicals. However, this pathway is a poor $\mathrm{OH}$ source. Because the vinyl 
hydroperoxides (M4H1_S) formed in this pathway is easily to collisionally stabilized under atmospheric condition and thus impeded $\mathrm{OH}$ formation [67,68].

M1H1_S can also evolve via the transition state TSM12H1_S (formation of $\alpha$-hydroxy hydroperoxide or reaction (2)), into a $\alpha$-hydroxy hydroperoxide M3H1_S. In this case, the formation of transition state TSM12H1_S is associated with the evolution of five-membered ring from the M1H1_S, where O8-H10 group and $\mathrm{H} 9$ atom belonging to the water move towards the $\mathrm{C} 1$ atom and the terminal oxygen atom $(\mathrm{O} 4)$ of the $\mathrm{C1O} 3 \mathrm{O} 4$ group belonging to stabCI-OO, respectively. There are also significant changes in the length of the main bonds. In particular, the O4-H9 bond length (1.408 $\AA$ ) in the corresponding transition (TSM12H1_S) complex decreases by $0.429 \AA$ and O8-H9 bond $(1.103 \AA)$ increases by $0.121 \AA$ compared with those in M1H1_S. The distance between $\mathrm{C} 1$ and $\mathrm{O} 8$ in the TSM12H1_S is $2.037 \AA$. Then, the $\alpha$-hydroxy hydroperoxide M1H1_S can be formed according to the following scheme: both $\mathrm{C} 1-\mathrm{O} 8$ and $\mathrm{O} 4-\mathrm{H} 9$ distances in the TSM12H1_S continue to decrease,

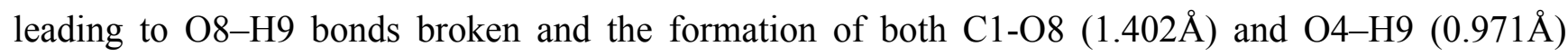
bonds in the M3H1_S.

The M3H1_S has six different reaction pathways (b1H1_S-b6H1_S). In the reaction pathway b1H1_S, M3H1_s initially evolves via the transition state TSM31H1_S. Then, the O3-O4 bond $(2.452 \AA)$ of TSM31H1_S is broken and the formation of R2H1_S and O4H9 radicals occurs. The b1H1_S of reaction (2) may be considered as another possible source of atmospheric $\mathrm{OH}$ radicals.

In the reaction pathway b2H1_S/b3H1_S, M3H1_S evolves via the transition state TSM32H1_S/ TSM33H1_S, yielding M5H1_S/M6H1_S. This process occurs according to the following scheme: the $\mathrm{H} 5 / \mathrm{H} 6$ connected to $\mathrm{C} 2$ moves towards $\mathrm{O} 4-\mathrm{H} 9$ group, while $\mathrm{H} 7$ linked to $\mathrm{C} 1$ migrates to $\mathrm{C} 2$ instead of H5/H6. After both O4-H5/O4-H6 (0.967 $\AA / 0.965 \AA)$ and C2-H7 (1.093 $\AA / 1.906 \AA)$ bonds are formed, the formation of M5H1_S/M6H1_S is completed. The O3-O4 bond increases to $2.274 \AA / 2.268 \AA$ in TSM32H1_S/TSM33H1_S, and elongates to $3.148 \AA / 2.923 \AA$ in M5H1_S/M6H1_S. Finally, the O3-O4 bond in the M5H1_S/M6H1_S is broken, leading to the formation of limononic acid A/limononic acid B and water. The reaction pathway b4H1_S is similar to b2H1_S. H7 connected to $\mathrm{C} 1$ migrates to the $\mathrm{O} 4-\mathrm{H} 9$ group, forming $\mathrm{O} 4-\mathrm{H} 7$ bond. The M3H1_S transforms via the transition state TSM34H1_S, into M7H1_S. Finally, the limononic acid C and water are formed from M7H1_S. The reaction pathway b5H1_S is quite similar to b2H1_S. However, in contrast to the b2H1_S, H7 connected to $\mathrm{C} 1$ moves towards $\mathrm{O} 3$, while $\mathrm{H} 10$ bonded to $\mathrm{O} 8$ migrates to O4-H9 group. After O8-H10 bond is broken and both O3-H7 (0.989 $\AA)$ and O4-H10 (0.975 $\AA)$ bonds are formed, the formation M8H1_S is completed. Then, the O3-O4 bond in the M8H1_S gets broken, leading to the formation of limononic acid D and water. In the reaction pathway b6H1_S, M3H1_S evolves via the transition state TSM36H1_S, into M9H1_S. This process occurs according to the following scheme: $\mathrm{H} 10$ connected to $\mathrm{O} 8$ moves towards $\mathrm{O} 3$ and the distance of O8-H10 increases by $0.720 \AA$ reaching $1.687 \AA$, while the $\mathrm{C} 1-\mathrm{O} 3$ bond is elongated by $1.980 \AA$ reaching $3.411 \AA$ in TSM36H1_S. TSM36H1_S then transforms into M9H1_S as the H10 connected to O8 continue to move towards O3 and the distance of $\mathrm{O} 8-\mathrm{H} 10$ gets increased to $1.839 \AA$, while the $\mathrm{C} 1-\mathrm{O} 3$ distance increases to $3.477 \AA$. After the O3-H10 bond $(0.983 \AA)$ is formed, the formation of M9H1_S is completed. Finally, the limonoaldehyde and $\mathrm{H}_{2} \mathrm{O}_{2}$ are formed from M9H1_S. The b6H1_S can also be considered as a possible source of atmospheric $\mathrm{H}_{2} \mathrm{O}_{2}$. 
Scheme 3 and Figure 2 show that the reaction of stabCI- $\mathrm{CH}_{3}-\mathrm{OO}$ with $\mathrm{H}_{2} \mathrm{O}$ exhibits the same behavior as stabCI-OO $+\mathrm{H}_{2} \mathrm{O}$ reaction. At the first step, the reacting stabCI- $\mathrm{CH}_{3}-\mathrm{OO}$ and $\mathrm{H}_{2} \mathrm{O}$ evolve into a hydrogen-bond $\mathrm{M} 1 \mathrm{H} 2$ _S complex of seven-membered ring. The M1H2_S finally transforms via the transition state TSM11H2_S (reaction (1)) into $\mathrm{OH}$ and R1H2_S radicals (pathway (aH2_S)) and via the TSM12H2_S (reaction (2)) into $\mathrm{OH}$ radical, R2H2_S radical, $\mathrm{H}_{2} \mathrm{O}, \mathrm{R} 3 \mathrm{H} 2 \_\mathrm{S}, \mathrm{R} 4 \mathrm{H} 2$ _S, limononaldehyde and $\mathrm{H}_{2} \mathrm{O}_{2}$ (pathway (b1H2_S-b3H2_S)).

Figure 2. Geometries of the stationary points in the stabCI-CH $\mathrm{CH}_{3}-\mathrm{OO}+\mathrm{H}_{2} \mathrm{O}$ reaction obtained at the B3LYP/6-31G(d,p) level of theory. Bond lengths and intermolecular distances are given in $\AA$.
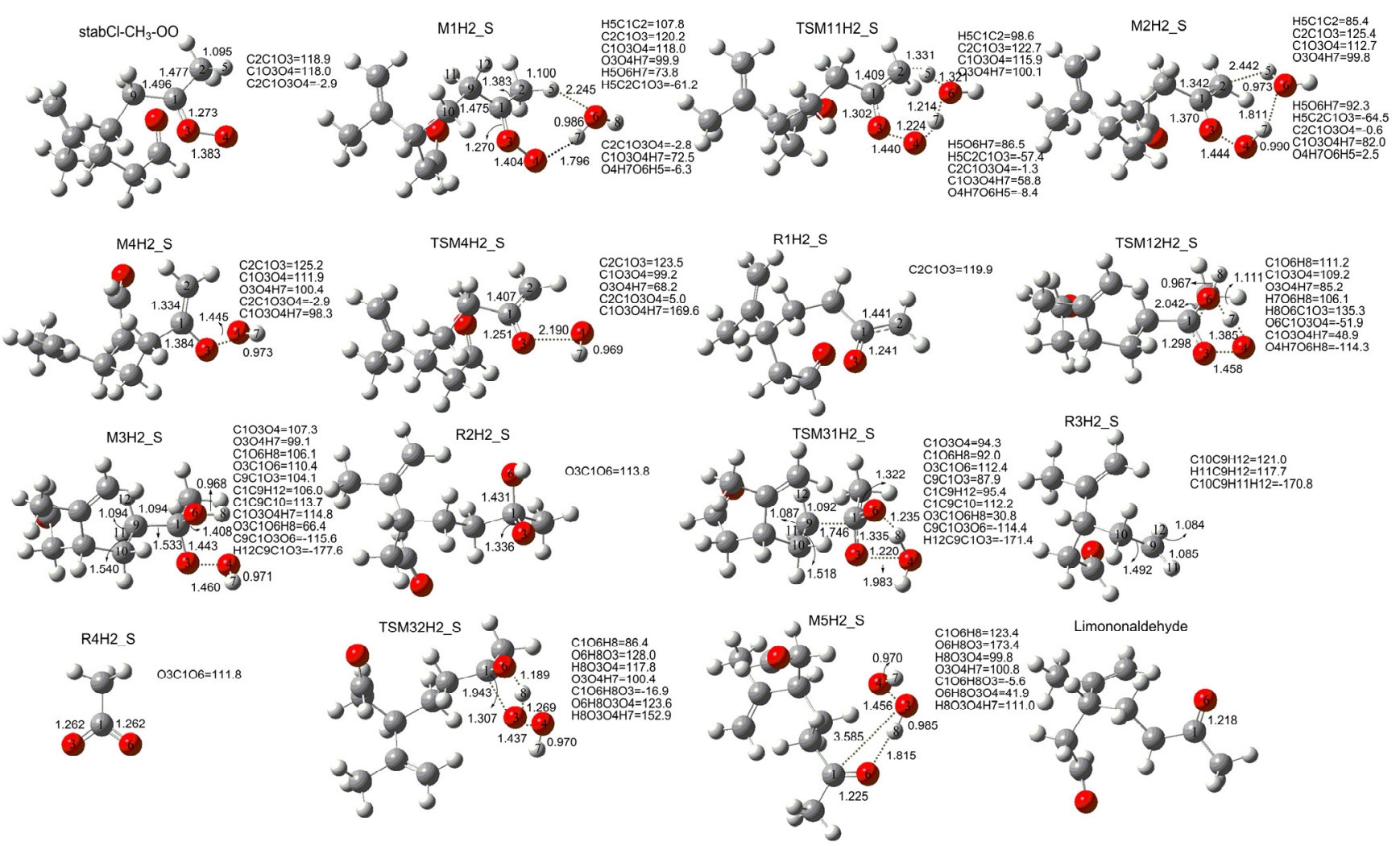

Scheme 4 and Figure 3 also show that the reaction between stabCI $x$-OO and $\mathrm{H}_{2} \mathrm{O}$ exhibits the same pattern and occurs according to the same scheme as those for the reaction between stabCI- $\mathrm{CH}_{3}-\mathrm{OO}$ and $\mathrm{H}_{2} \mathrm{O}$. The reaction between stabCI $x$-OO and $\mathrm{H}_{2} \mathrm{O}$ leads to the formation of a hydrogen-bonded M1H3_S complex with seven-membered ring. Finally, the M1H3_S finally evolves via the transition states TSM11H3_S (reaction (1)) and TSM12H3_S (reaction (2)) into OH radical, R1H3_S radical, R2H3_S radical, R3H3_S, R4H3_S, $\mathrm{H}_{2} \mathrm{O}$, Keto-limonene and $\mathrm{H}_{2} \mathrm{O}_{2}$. 
Figure 3. Geometries of the stationary points in the stabCIx-OO $+\mathrm{H}_{2} \mathrm{O}$ reaction obtained at the B3LYP/6-31G(d,p) level of theory. Bond lengths and intermolecular distances are given in $\AA$.
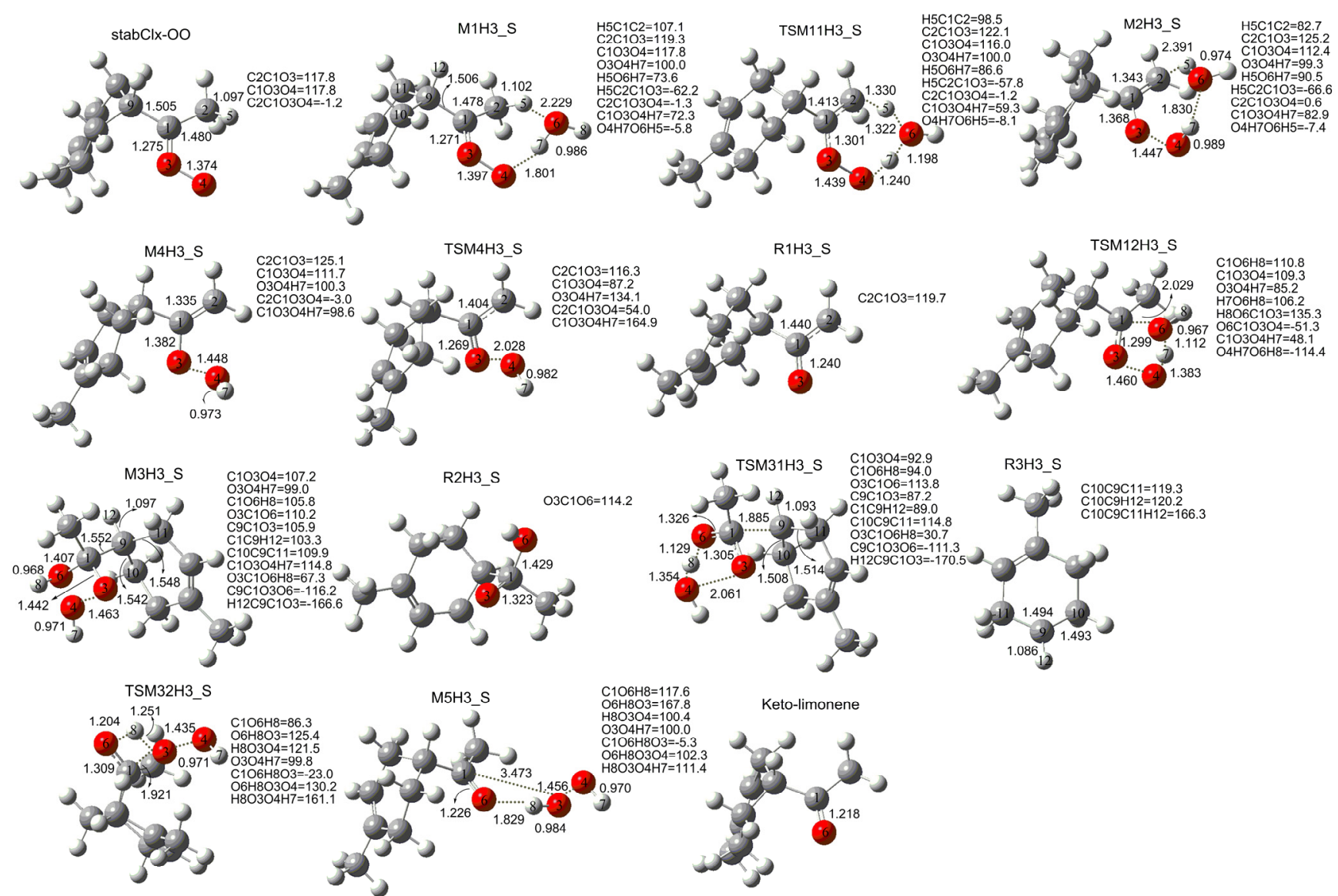

\subsection{Thermochemical Analysis}

Although the higher level $\operatorname{CCSD}(\mathrm{T}) / 6-31 \mathrm{G}(\mathrm{d})+\mathrm{CF}$ method has been chosen as a principal computational method for the present study, in order to ensure the quality of the obtained results and to validate the obtained conclusions, reaction and activation energies for the reaction between stabCl-OO and $\mathrm{H}_{2} \mathrm{O}$ with the Zero-Point Correction (ZPE) included were also calculated using several other methods used to study the similar systems in the past. The results of the present study are given in Table 1. As it may be seen from Table 1, the reaction and activation energies calculated at different levels are in qualitative agreement in most of the cases studied (not exceed $10 \mathrm{kcal} \mathrm{mol}^{-1}$ ). Only in a few cases, such as the energy of TSM31H1_S relative to $\mathrm{M} 3 \mathrm{H} 1$ S , the values predicted B3LYP/6-31G(d,p), MP2/6-31G(d), MP2/6-311++G(d,p) and CCSD(T)/6-31G(d) are quite different from those given by the $\operatorname{CCSD}(\mathrm{T}) / 6-31 \mathrm{G}(\mathrm{d})+\mathrm{CF}$ with the differences of $23.75 \mathrm{kcal} \mathrm{mol}^{-1}$, $21.22 \mathrm{kcal} \mathrm{mol}^{-1}, 27.14 \mathrm{kcal} \mathrm{mol}^{-1}$ and $2.53 \mathrm{kcal} \mathrm{mol}^{-1}$ respectively, presumably most accurate method used in the present study. 
Table 1. Reaction and activation energies $(E)$ with Zero-Point Correction (ZPE) included $\left(\mathrm{kcal} \mathrm{mol}^{-1}\right)$ ) for the reaction between stabCl-OO and $\mathrm{H}_{2} \mathrm{O}^{\text {a }}$ at different levels of theory.

\begin{tabular}{|c|c|c|c|c|c|c|}
\hline Compound & Relative to & $\begin{array}{c}E(B 3 L Y P / \\
\text { 6-31G(d,p)) }\end{array}$ & $\begin{array}{c}E(\mathrm{MP2} / \\
\text { 6-31G(d)) }\end{array}$ & $\begin{array}{c}E(\mathrm{MP} 2 / \\
6-311++G(d, p))\end{array}$ & $\begin{array}{c}E(\operatorname{CCSD}(\mathrm{T}) / \\
6-31 G(d)) \\
\end{array}$ & $\begin{array}{c}E(\mathrm{CCSD}(\mathrm{T}) / \\
6-31 G(\mathrm{~d})+\mathrm{CF})\end{array}$ \\
\hline stabCl-OO $+\mathrm{H}_{2} \mathrm{O}$ & & 0.00 & 0.00 & 0.00 & 0.00 & 0.00 \\
\hline M1H1_S & $\begin{array}{c}\text { stabCl-OO }+ \\
\mathrm{H}_{2} \mathrm{O}\end{array}$ & -8.65 & -7.27 & -7.54 & -7.54 & -6.16 \\
\hline TSM11H1_S & M1H1_S & 13.27 & 11.44 & 8.52 & 18.51 & 16.68 \\
\hline M2H1_S & TSM11H1_S & -34.17 & -34.57 & -26.94 & -35.09 & -35.50 \\
\hline $\mathrm{M} 4 \mathrm{H} 1 \_\mathrm{S}+\mathrm{H}_{2} \mathrm{O}$ & M2H1_S & 8.80 & 5.64 & 8.50 & 7.91 & 4.74 \\
\hline TSM4H1_S & M4H1_S & 24.29 & 18.38 & 29.60 & 20.51 & 14.60 \\
\hline $\mathrm{R} 1 \mathrm{H} 1 \_\mathrm{S}+\mathrm{OH}$ & TSM4H1_S & -10.64 & -8.29 & -17.17 & -9.39 & -7.04 \\
\hline TSM12H1_S & M1H1_S & 14.96 & 17.01 & 13.62 & 16.78 & 18.83 \\
\hline M3H1_S & TSM12H1_S & -50.15 & -50.35 & -41.65 & -47.92 & -48.12 \\
\hline TSM31H1_S & M3H1_S & 56.79 & 54.26 & 60.18 & 35.57 & 33.04 \\
\hline $\mathrm{R} 2 \mathrm{H} 1 \_\mathrm{S}+\mathrm{OH}$ & TSM31H1_S & -12.35 & -12.64 & -22.88 & 2.06 & 1.78 \\
\hline TSM32H1_S & M3H1_S & 40.23 & 32.82 & 46.83 & 49.85 & 42.44 \\
\hline M5H1_S & TSM32H1_S & -121.60 & -120.87 & -124.12 & -126.25 & -125.52 \\
\hline $\begin{array}{l}\text { Limononic acid } \\
\qquad \mathrm{A}+\mathrm{H}_{2} \mathrm{O}\end{array}$ & M5H1_S & 7.41 & 5.01 & 6.31 & 7.12 & 4.71 \\
\hline TSM33H1_S & M3H1_S & 44.84 & 35.62 & 51.29 & 54.09 & 44.87 \\
\hline M6H1_S & TSM33H1_S & -121.88 & -120.57 & -126.09 & -126.76 & -125.44 \\
\hline $\begin{array}{l}\text { Limononic acid B } \\
\qquad+\mathrm{H}_{2} \mathrm{O}\end{array}$ & M6H1_S & 5.84 & 3.56 & 5.60 & 5.53 & 3.24 \\
\hline TSM34H1_S & M3H1_S & 53.34 & 48.18 & 51.67 & 52.07 & 46.91 \\
\hline M7H1_S & TSM34H1_S & -130.73 & -131.72 & -126.97 & -124.94 & -125.93 \\
\hline $\begin{array}{l}\text { Limononic acid } \mathrm{C} \\
++\mathrm{H}_{2} \mathrm{O}\end{array}$ & M7H1_S & 8.06 & 4.72 & 7.79 & 7.56 & 4.22 \\
\hline TSM35H1_S & M3H1_S & 44.65 & 42.72 & 34.16 & 43.70 & 41.78 \\
\hline M8H1_S & TSM35H1_S & -125.34 & -129.75 & -111.65 & -119.40 & -123.81 \\
\hline $\begin{array}{l}\text { Limononic acid } \\
\qquad \mathrm{D}+\mathrm{H}_{2} \mathrm{O}\end{array}$ & M8H1_S & 8.44 & 6.46 & 7.78 & 8.03 & 6.05 \\
\hline TSM36H1_S & M3H1_S & 54.94 & 55.16 & 49.52 & 52.33 & 52.55 \\
\hline M9H1_S & TSM36H1_S & -51.97 & -51.66 & -47.33 & -49.38 & -49.07 \\
\hline $\begin{array}{l}\text { Limononaldehyd } \\
\qquad \mathrm{e}+\mathrm{H}_{2} \mathrm{O}_{2} \\
\end{array}$ & M9H1_S & 8.58 & 6.79 & 8.12 & 8.26 & 6.47 \\
\hline
\end{tabular}

${ }^{\text {a }}$ Optimized geometries, vibrational frequencies and ZPE obtained at the B3LYP/6-31G(d,p) level.

As seen from Table 1 and Figure 4, the most accurate and higher level CCSD(T)/6-31G(d) $+\mathrm{CF}$ method show that the initial hydrogen-bond complex M1H1_S is $6.16 \mathrm{kcal} \mathrm{mol}^{-1}$ more stable than the separate stabCl-OO and $\mathrm{H}_{2} \mathrm{O}$. For the reaction of stabCI-OO with $\mathrm{H}_{2} \mathrm{O}$, the formation of $\alpha$-hydroxy hydroperoxide (reaction (2)) $\left(-35.45 \mathrm{kcal} \mathrm{mol}^{-1}\right)$ is more favorable than the formation of $\mathrm{OH}$ radicals with water-catalyzed $\mathrm{H}$ migration path (reaction (1)) (-24.98 $\mathrm{kcal} \mathrm{mol}^{-1}$ ) (see Figure 4) The energies for the reaction pathways aH1_S and b1H1_S associated with the formation of $\mathrm{OH}$ radical are $12.67 \mathrm{kcal} \mathrm{mol}^{-1}$ and $0.63 \mathrm{kcal} \mathrm{mol}^{-1}$, respectively. Among the seven reaction pathways 
(aH1_S-b6H1_S), the pathways (aH1_S and b1H1_S) for the formation of OH radical are by $12.67 \mathrm{kcal} \mathrm{mol}^{-1}$ and $0.63 \mathrm{kcal} \mathrm{mol}^{-1}$ more stable than the separate stabCI-OO and $\mathrm{H}_{2} \mathrm{O}$, the pathway (b6H1_S) for formation of limonoaldehyde and $\mathrm{H}_{2} \mathrm{O}_{2}$ is by $25.49 \mathrm{kcal} \mathrm{mol}^{-1}$ more stable than the separate stabCI-OO and $\mathrm{H}_{2} \mathrm{O}$, and the four pathways (b2H1_S-b5H1_S) for formation of limononic acid and water are by $110.25-113.82 \mathrm{kcal} \mathrm{mol}^{-1}$ more stable than the separate stabCI-OO and $\mathrm{H}_{2} \mathrm{O}$. The differences in the reaction energies are close and agree within $3.57 \mathrm{kcal} \mathrm{mol}^{-1}$ for all the four pathways (b2H1_S-b5H1_S).

Figure 4. stabCI-OO $+\mathrm{H}_{2} \mathrm{O}$ reaction coordinates: relative energies of the stationary points located on the separate stabCI-OO and $\mathrm{H}_{2} \mathrm{O}$ ground-state potential energy surface. The energy values are given in $\mathrm{kcal} \mathrm{mol}^{-1}$ and were calculated using $\operatorname{CCSD}(\mathrm{T}) / 6-31 \mathrm{G}(\mathrm{d})+$ CF//B3LYP/6-31G(d,p) level.

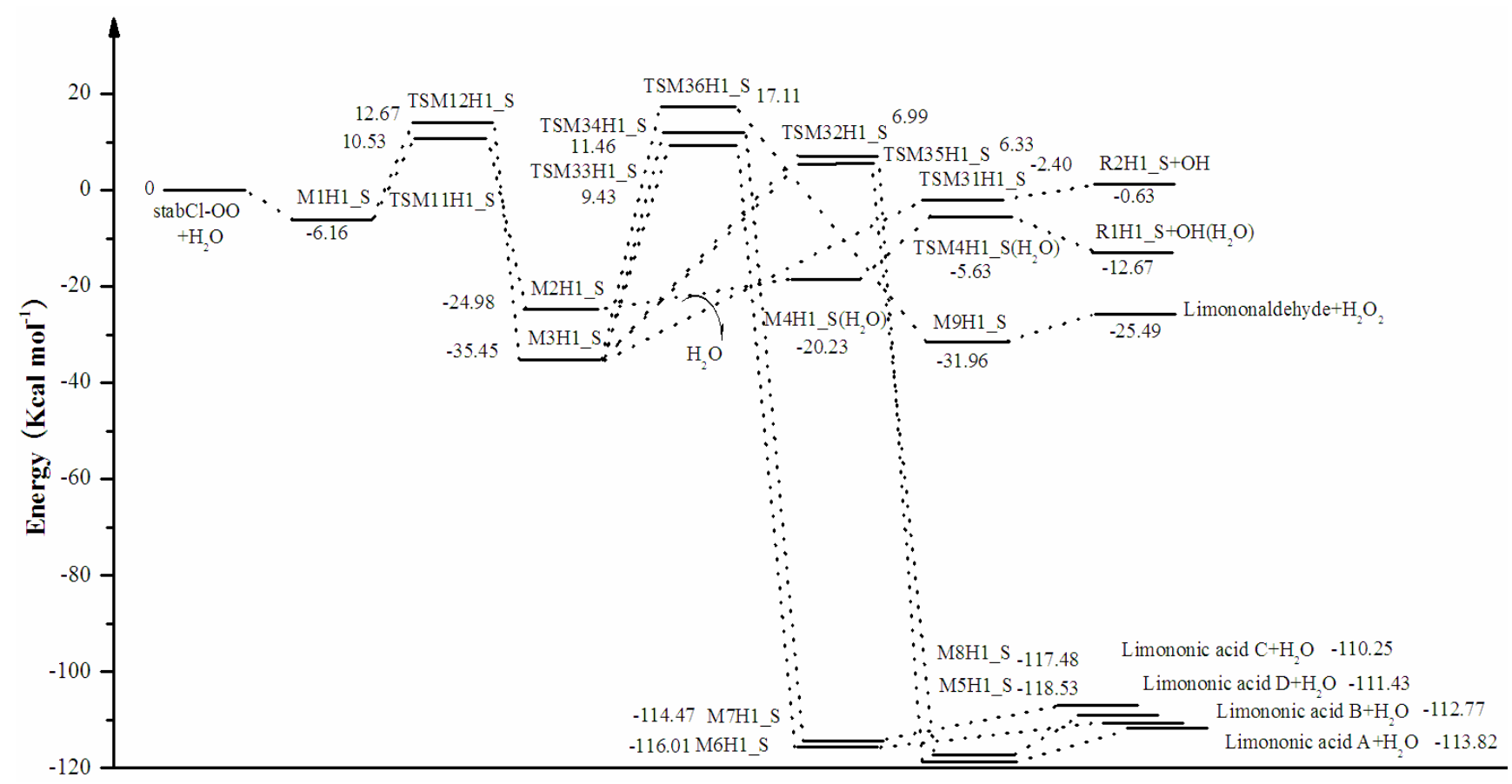

With respect to the corresponding $\mathrm{M} 1 \mathrm{H} 1 \_\mathrm{S}$, the activation energy for the formation of $\mathrm{OH}$ radicals with water-catalyzed $\mathrm{H}$ migration path (reaction (1)) (16.69 $\mathrm{kcal} \mathrm{mol}^{-1}$ ) is smaller than that for the formation of $\alpha$-hydroxy hydroperoxide (reaction (2)) (18.83 kcal mol${ }^{-1}$ ), indicating that the formation of $\mathrm{OH}$ radicals with water-catalyzed $\mathrm{H}$ migration path (reaction (1)) is slightly more favorable than the formation of $\alpha$-hydroxy hydroperoxide (reaction (2)). Thus, with the reaction between our optimized stabCI-OO (syn stabCI-OO) and water, this conclusion is opposite to that obtained in the earlier theoretical study of the reaction between isoprene stabilized Criegee intermediates and $\mathrm{H}_{2} \mathrm{O}$ by Anglada [37]. Since in Anglada's study [37], the energies for the reaction of water with all the eight isoprene stabilized Criegee intermediates have been calculated using G2(G2M-RCC5) method [38] with all stationary points optimized using the B3LYP/6-311+G(2d,2p) and neither comprehensive benchmarks for aforementioned method [38] nor a comparison between the prediction of the $\operatorname{CCSD}(\mathrm{T}) / 6-31 \mathrm{G}(\mathrm{d})+\mathrm{CF} / / \mathrm{B} 3 \mathrm{LYP} / 6-31 \mathrm{G}(\mathrm{d}, \mathrm{p})$ method and G2M-RCC5//B3LYP/6-311+G(2d,2p) methods are available at the present time, the activation energies between reaction (1) and reaction (2) 
for stabCI-OO and $\mathrm{H}_{2} \mathrm{O}$ obtained at the $\mathrm{B} 3 \mathrm{LYP} / 6-31 \mathrm{G}(\mathrm{d}, \mathrm{p}) / / \mathrm{B} 3 \mathrm{LYP} / 6-31 \mathrm{G}(\mathrm{d}, \mathrm{p})$, MP2/6-31G(d)//B3LYP/6-31G(d,p), MP2/6-311++G(d,p)//B3LYP/6-31G(d,p) and CCSD(T)/6$31 \mathrm{G}(\mathrm{d}) / / \mathrm{B} 3 \mathrm{LYP} / 6-31 \mathrm{G}(\mathrm{d}, \mathrm{p})$ levels of theory in the present study were used to validate our conclusion. The comparison, which indicates that the reaction (1) is more favorable than reaction (2) for stabCI-OO and $\mathrm{H}_{2} \mathrm{O}$ in all the cases studied (expect for the $\operatorname{CCSD}(\mathrm{T}) / 6-31 \mathrm{G}(\mathrm{d}) / / \mathrm{B} 3 \mathrm{LYP} /$ 6-31G(d,p)) method) largely confirms our conclusion.

The activation energies of the six subsequent reaction pathways for the formation of $\alpha$-hydroxy hydroperoxide (reaction (2)) are in the range of 33.04-52.55 kcal mol${ }^{-1}$ with respect to corresponding M3H1_S, with the b1H1_S as the most favorable pathway of the activation energy of $33.04 \mathrm{kcal} \mathrm{mol}^{-1}$. The activation energies for the four pathways (b2H1_S-b5H1_S) are in the range of $41.78-46.91 \mathrm{kcal} \mathrm{mol}^{-1}$, and the differences between them are quite small $\left(<3.578 \mathrm{kcal} \mathrm{mol}^{-1}\right)$. Figure 4 illustrates the relative energies of the stationary points located on the singlet ground-state the separate stabCI-OO and $\mathrm{H}_{2} \mathrm{O}$ potential energy surface at the CCSD(T)/6-31G(d) + CF level of theory.

Reaction and activation energies for the reaction between stabCI- $\mathrm{CH}_{3}-\mathrm{OO}$ and $\mathrm{H}_{2} \mathrm{O}$ with the Zero-Point Correction (ZPE) included were calculated at different levels of theory. The results of the calculations are presented in Table 2. As it may be seen from Table 2 and Figure 5, the higher level $\operatorname{CCSD}(\mathrm{T}) / 6-31 \mathrm{G}(\mathrm{d})+\mathrm{CF}$ predicts that the initial hydrogen-bond complex M1H2_S is $6.35 \mathrm{kcal} \mathrm{mol}^{-1}$ more stable than the separate stabCI-CH$-\mathrm{CH}_{3}-\mathrm{OO}$ and $\mathrm{H}_{2} \mathrm{O}$. For the reaction of stabCI-CH${ }_{3}-\mathrm{OO}$ with $\mathrm{H}_{2} \mathrm{O}$, the formation of $\alpha$-hydroxy hydroperoxide (reaction (2)) $\left(-32.17 \mathrm{kcal} \mathrm{mol}^{-1}\right)$ is more stable than the formation of $\mathrm{OH}$ radicals with the water-catalyzed $\mathrm{H}$ migration path (reaction (1)) $\left(-16.70 \mathrm{kcal} \mathrm{mol}^{-1}\right.$ ). (See Figure 5) In the case of the four following reaction pathways (aH2_S-b3H2_S), the reaction energies with the respect to corresponding to the separated stabCI- $\mathrm{CH}_{3}-\mathrm{OO}$ and $\mathrm{H}_{2} \mathrm{O}$, are $-3.03 \mathrm{kcal} \mathrm{mol}^{-1},-3.46 \mathrm{kcal} \mathrm{mol}^{-1},-10.25 \mathrm{kcal} \mathrm{mol}^{-1}$ and $-21.30 \mathrm{kcal} \mathrm{mol}^{-1}$, respectively. The activation energies for the formation of $\mathrm{OH}$ radicals from $\mathrm{M} 1 \mathrm{H} 2$ _S via water-catalyzed $\mathrm{H}$ migration path (reaction (1)) (21.98 kcal mol $\left.{ }^{-1}\right)$ is larger than those for the formation of $\alpha$-hydroxy hydroperoxide (reaction (2)) (15.53 kcal mol${ }^{-1}$ ). This indicates that the formation of $\alpha$-hydroxy hydroperoxide (reaction (2)) is more favorable than the formation of $\mathrm{OH}$ radicals with water-catalyzed $\mathrm{H}$ migration path (reaction (1)). The differences in the activation energies between reaction (1) and reaction (2) for stabCI-CH${ }_{3}-\mathrm{OO}$ and $\mathrm{H}_{2} \mathrm{O}$ obtained at the $\mathrm{B} 3 \mathrm{LYP} / 6-31 \mathrm{G}(\mathrm{d}, \mathrm{p}) / / \mathrm{B} 3 \mathrm{LYP} / 6-31 \mathrm{G}(\mathrm{d}, \mathrm{p})$, MP2/6-31G(d)//B3LYP/6-31G(d,p), MP2/6-311++G(d,p)//B3LYP/6-31G(d,p) and CCSD(T)/6$31 \mathrm{G}(\mathrm{d}) / / \mathrm{B} 3 \mathrm{LYP} / 6-31 \mathrm{G}(\mathrm{d}, \mathrm{p})$ levels of theory also indicate that the reaction (2) is more favorable than reaction (1) for stabCI-OO and $\mathrm{H}_{2} \mathrm{O}$. This conclusion is in agreement with the previous theoretical study of the reaction between isoprene stabilized Criegee intermediates and $\mathrm{H}_{2} \mathrm{O}$ by Anglada [37].

The activation energies of the three subsequent reaction pathways for the formation of $\alpha$-hydroxy hydroperoxide (reaction (2)) are in the range of 35.63-44.04 $\mathrm{kcal} \mathrm{mol}^{-1}$ with respect to corresponding $\mathrm{M} 3 \mathrm{H} 2$ _S, with the b1H2_S as the most favorable pathway with the activation energy of $35.63 \mathrm{kcal} \mathrm{mol}^{-1}$. Figure 5 illustrates the relative energies of the stationary points located on the singlet ground-state the separate stabCI- $\mathrm{CH}_{3}-\mathrm{OO}$ and $\mathrm{H}_{2} \mathrm{O}$ potential energy surface at the $\mathrm{CCSD}(\mathrm{T}) / 6-31 \mathrm{G}(\mathrm{d})$ + CF level of theory. 
Table 2. Reaction and activation energies $(E)$ with Zero-Point Correction (ZPE) included $\left(\mathrm{kcal} \mathrm{mol}^{-1}\right)$ for the reaction between stabCl- $\mathrm{CH}_{3}-\mathrm{OO}$ and $\mathrm{H}_{2} \mathrm{O}^{\text {a }}$ at different levels of theory.

\begin{tabular}{|c|c|c|c|c|c|c|}
\hline Compound & Relative to & $\begin{array}{r}E(B 3 L Y P / \\
6-31 G(d, p))\end{array}$ & $\begin{array}{l}E G(M P 2 / \\
6-31 G(d)) \\
\end{array}$ & $\begin{array}{c}E(\text { MP2/ } \\
6-311++G(d, p))\end{array}$ & $\begin{array}{c}E(\operatorname{CCSD}(\mathrm{T}) \\
/ 6-31 \mathrm{G}(\mathrm{d})) \\
\end{array}$ & $\begin{array}{c}E(\operatorname{CCSD}(\mathrm{T}) / \\
6-31 \mathrm{G}(\mathrm{d})+\mathrm{CF})\end{array}$ \\
\hline stabCl- $\mathrm{CH}_{3}-\mathrm{OO}+\mathrm{H}_{2} \mathrm{O}$ & & 0.00 & 0.00 & 0.00 & 0.00 & 0.00 \\
\hline M1H2_S & $\begin{array}{l}\text { stabCl- } \mathrm{CH}_{3^{-}} \\
\mathrm{OO}+\mathrm{H}_{2} \mathrm{O}\end{array}$ & -11.15 & -7.94 & -10.45 & -9.57 & -6.35 \\
\hline TSM11H2_S & M1H2_S & 19.60 & 16.93 & 14.68 & 24.64 & 21.98 \\
\hline M2H2_S & TSM11 & -30.19 & -31.48 & -22.41 & -31.04 & -32.32 \\
\hline $\mathrm{M} 4 \mathrm{H} 2 \_\mathrm{S}+\mathrm{H}_{2} \mathrm{O}$ & M2H2_S & 8.74 & 5.66 & 8.71 & 7.86 & 4.79 \\
\hline TSM4H2_S & M4H2_S & 29.25 & 25.80 & 41.29 & 20.30 & 16.86 \\
\hline $\mathrm{R} 1 \mathrm{H} 2 \_\mathrm{S}+\mathrm{OH}$ & TSM4H2_S & -17.41 & -15.58 & -28.27 & -9.81 & -7.98 \\
\hline TSM12H2_S & M1H2_S & 11.72 & 13.61 & 11.25 & 13.64 & 15.53 \\
\hline M3H2_S & TSM12H2_S & -43.36 & -43.58 & -34.17 & -41.13 & -41.35 \\
\hline $\mathrm{R} 2 \mathrm{H} 2 \_\mathrm{S}+\mathrm{OH}$ & M3H2_S & 46.53 & 43.33 & 38.15 & 38.84 & 35.63 \\
\hline TSM31H2_S & M3H2_S & 45.47 & 43.40 & 37.90 & 46.11 & 44.04 \\
\hline $\begin{array}{c}\mathrm{R} 3 \mathrm{H} 2 \_\mathrm{S}+\mathrm{R} 4 \mathrm{H} 2 \_\mathrm{S}+ \\
\mathrm{H}_{2} \mathrm{O}\end{array}$ & TSM31H2_S & -20.33 & -22.99 & -21.49 & -19.45 & -22.11 \\
\hline TSM32H2_S & M3H2_S & 44.87 & 43.12 & 36.08 & 44.51 & 42.76 \\
\hline M5H2_S & TSM32H2_S & -41.41 & -39.53 & -35.87 & -41.49 & -39.62 \\
\hline $\begin{array}{c}\text { Limononaldehyde }+ \\
\mathrm{H}_{2} \mathrm{O}_{2} \\
\end{array}$ & M5H2_S & 9.16 & 8.17 & 8.14 & 8.72 & 7.73 \\
\hline
\end{tabular}

${ }^{\mathrm{a}}$ Optimized geometries, vibrational frequencies and ZPE obtained at the B3LYP/6-31G(d,p) level.

Reaction and activation energies for the reaction between stabCI $x$-OO and $\mathrm{H}_{2} \mathrm{O}$ with the Zero-Point Correction (ZPE) included calculated at different levels of theory are shown in Table 3. Table 3 and Figure 6 demonstrate that the values of reaction and activation for the reaction between stabCI $x$-OO and $\mathrm{H}_{2} \mathrm{O}$ correlate with those of reaction and activation energies for the reaction of stabCI-CH$-\mathrm{OO}$ and $\mathrm{H}_{2} \mathrm{O}$. The formation of $\alpha$-hydroxy hydroperoxide (reaction (2)) is more favorable than the formation of $\mathrm{OH}$ radicals with water-catalyzed $\mathrm{H}$ migration path or reaction (1). The differences in the activation energies between reaction (1) and reaction (2) for stabCIx-OO and $\mathrm{H}_{2} \mathrm{O}$ obtained at the B3LYP/6-31G(d,p)//B3LYP/6-31G(d,p), MP2/6-31G(d)//B3LYP/6-31G(d,p), MP2/6-311++ $\mathrm{G}(\mathrm{d}, \mathrm{p}) / / \mathrm{B} 3 \mathrm{LYP} / 6-31 \mathrm{G}(\mathrm{d}, \mathrm{p})$ and $\operatorname{CCSD}(\mathrm{T}) / 6-31 \mathrm{G}(\mathrm{d}) \quad / / \mathrm{B} 3 \mathrm{LYP} / 6-31 \mathrm{G}(\mathrm{d}, \mathrm{p})$ levels of theory (4.06 kcal mol ${ }^{-1}, 0.12 \mathrm{kcal} \mathrm{mol}^{-1},-0.73 \mathrm{kcal} \mathrm{mol}^{-1}$ and $7.16 \mathrm{kcal} \mathrm{mol}^{-1}$, respectively) also indicate (with exception for MP2/6-311++G(d,p)//B3LYP/6-31G(d,p) method) that the reaction (2) is likely more favorable than reaction (1) for stabCIx-OO and $\mathrm{H}_{2} \mathrm{O}$. These findings are consistent with the previous theoretical study of the reaction between isoprene stabilized Criegee intermediates and $\mathrm{H}_{2} \mathrm{O}$ by Anglada [37]. Figure 6 illustrates the relative energies of the stationary points located on the singlet ground-state the separate stabCI $x$-OO and $\mathrm{H}_{2} \mathrm{O}$ potential energy surface at the $\mathrm{CCSD}(\mathrm{T}) / 6-31 \mathrm{G}(\mathrm{d})+$ CF level of theory. 
Figure 5. StabCI-CH$-\mathrm{CH}_{3}-\mathrm{OO}+\mathrm{H}_{2} \mathrm{O}$ reaction coordinates: relative energies of the stationary points located on the separate stabCI-CH $\mathrm{CH}_{3}-\mathrm{OO}$ and $\mathrm{H}_{2} \mathrm{O}$ ground-state potential energy surface. The energy values are given in $\mathrm{kcal} \mathrm{mol}^{-1}$ and were calculated using $\operatorname{CCSD}(\mathrm{T}) / 6$ 31G(d) + CF//B3LYP/6-31G(d,p) level.

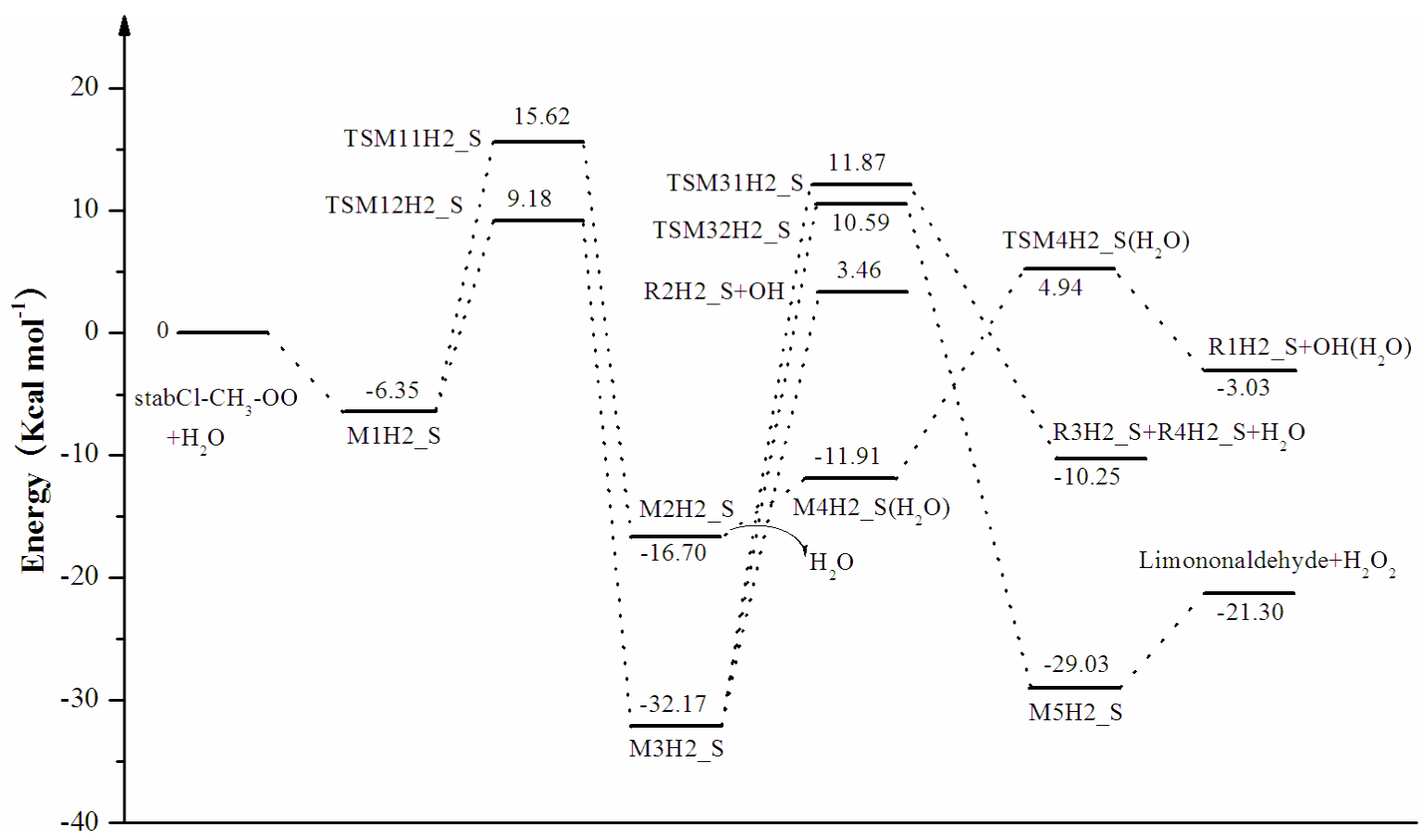

Table 3. Reaction and activation energies $(E)$ with Zero-Point Correction (ZPE) included $\left(\mathrm{kcal} \mathrm{mol}^{-1}\right.$ ) for the reaction between stabClx-OO and $\mathrm{H}_{2} \mathrm{O}^{\mathrm{a}}$ at different levels of theory.

\begin{tabular}{|c|c|c|c|c|c|c|}
\hline Compound & Relative to & $\begin{array}{c}E(B 3 L Y P / \\
\text { 6-31G(d,p)) }\end{array}$ & $\begin{array}{c}E(\mathrm{MP2} / \\
6-31 G(d))\end{array}$ & $\begin{array}{c}E(\mathrm{MP} 2 / \\
6-311++G(d, p))\end{array}$ & $\begin{array}{c}E(C C S D(T) \\
/ 6-31 G(d))\end{array}$ & $\begin{array}{c}E(C \operatorname{CSD}(\mathrm{T}) / \\
\text { 6-31G(d) + CF })\end{array}$ \\
\hline stabClx-OO $+\mathrm{H}_{2} \mathrm{O}$ & & 0.00 & 0.00 & 0.00 & 0.00 & 0.00 \\
\hline M1H3_S & $\begin{array}{c}\text { stabClx-OO + } \\
\mathrm{H}_{2} \mathrm{O}\end{array}$ & -10.79 & -7.67 & -10.22 & -9.32 & -6.19 \\
\hline TSM11H3_S & M1H3_S & 15.56 & 12.93 & 11.36 & 20.55 & 17.92 \\
\hline M2H3_S & TSM11H3_S & -30.54 & -31.66 & -22.01 & -31.27 & -32.39 \\
\hline $\mathrm{M} 4 \mathrm{H} 3 \_\mathrm{S}+\mathrm{H}_{2} \mathrm{O}$ & M2H3_S & 9.31 & 6.32 & 8.79 & 8.35 & 5.36 \\
\hline TSM4H3_S & M4H3_S & 28.12 & 24.23 & 34.67 & 24.14 & 20.24 \\
\hline $\mathrm{R} 1 \mathrm{H} 3 \_\mathrm{S}+\mathrm{OH}$ & TSM4H3_S & -12.80 & -11.39 & -18.84 & -10.79 & -9.38 \\
\hline TSM12H3_S & M1H3_S & 11.50 & 12.81 & 12.09 & 13.39 & 14.70 \\
\hline M3H3_S & TSM12H3_S & -42.89 & -42.86 & -33.40 & -40.72 & -40.69 \\
\hline R2H3_S + OH & M3H3_S & 45.32 & 42.42 & 35.58 & 37.28 & 34.38 \\
\hline TSM31H3_S & M3H3_S & 41.90 & 38.07 & 34.61 & 43.19 & 39.36 \\
\hline $\begin{array}{c}\mathrm{R} 3 \mathrm{H} 3 \_\mathrm{S}+\mathrm{R} 4 \mathrm{H} 3 \_\mathrm{S}+ \\
\mathrm{H}_{2} \mathrm{O}\end{array}$ & TSM31H3_S & -19.76 & -20.40 & -24.55 & -20.32 & -20.95 \\
\hline TSM32H3_S & M3H3_S & 42.47 & 41.24 & 34.04 & 42.27 & 41.04 \\
\hline M5H3_S & TSM32H3_S & -40.78 & -38.49 & -36.13 & -41.14 & -38.86 \\
\hline $\begin{array}{c}\text { Keto-limonene }+ \\
\mathrm{H}_{2} \mathrm{O}_{2} \\
\end{array}$ & M5H3_S & 8.20 & 6.41 & 7.99 & 7.88 & 6.10 \\
\hline
\end{tabular}

\footnotetext{
${ }^{\text {a }}$ Optimized geometries, vibrational frequencies and ZPE obtained at the B3LYP/6-31G(d,p) level.
} 
As it may be seen from Tables 1-3, we can conclude that the energy of the initial hydrogen-bond complex (M1H1_S, M1H2_S, M1H3_S) are $6.16 \mathrm{kcal} \mathrm{mol}^{-1}, 6.35 \mathrm{kcal} \mathrm{mol}^{-1}$ and $6.19 \mathrm{kcal} \mathrm{mol}^{-1}$ more stable than the corresponding separate stabilized Criegee intermediates (stabCl-OO, stabCI-CH${ }_{3}-\mathrm{OO}$, stabCI $x$-OO) and $\mathrm{H}_{2} \mathrm{O}$ at the $\mathrm{CCSD}(\mathrm{T}) / 6-31 \mathrm{G}(\mathrm{d})+\mathrm{CF}$ level of theory. For the formation of $\mathrm{OH}$ radicals via the water-catalyzed $\mathrm{H}$ migration path (reaction (1)), the activation energies with the respect to hydrogen-bond complex (M1H1_S, M1H2_S, M1H3_S) are $16.68 \mathrm{kcal} \mathrm{mol}^{-1}, 21.98 \mathrm{kcal} \mathrm{mol}^{-1}$, and $17.92 \mathrm{kcal} \mathrm{mol}^{-1}$, respectively, with the reaction (1) for the reaction of stabCl-OO and $\mathrm{H}_{2} \mathrm{O}$ as the most favorable pathway $\left(16.68 \mathrm{kcal} \mathrm{mol}^{-1}\right)$. For the formation of $\alpha$-hydroxy hydroperoxide (reaction (2)), the activation energies are in the range of 14.70-18.83 $\mathrm{kcal} \mathrm{mol}^{-1}$ with respect to corresponding hydrogen-bond complex (M1H1_S, M1H2_S, M1H3_S), with the reaction (2) for stabCIx-OO $+\mathrm{H}_{2} \mathrm{O}$ reaction as the most favorable pathway $\left(14.70 \mathrm{kcal} \mathrm{mol}^{-1}\right)$.

Figure 6. stabCI $x$-OO $+\mathrm{H}_{2} \mathrm{O}$ reaction coordinates: relative energies of the stationary points located on the separate stabCI $x$-OO and $\mathrm{H}_{2} \mathrm{O}$ ground-state potential energy surface. The energy values are given in $\mathrm{kcal} \mathrm{mol}^{-1}$ and are calculated using $\operatorname{CCSD}(\mathrm{T}) / 6-31 \mathrm{G}(\mathrm{d})+$ CF//B3LYP/6-31G(d,p) level.

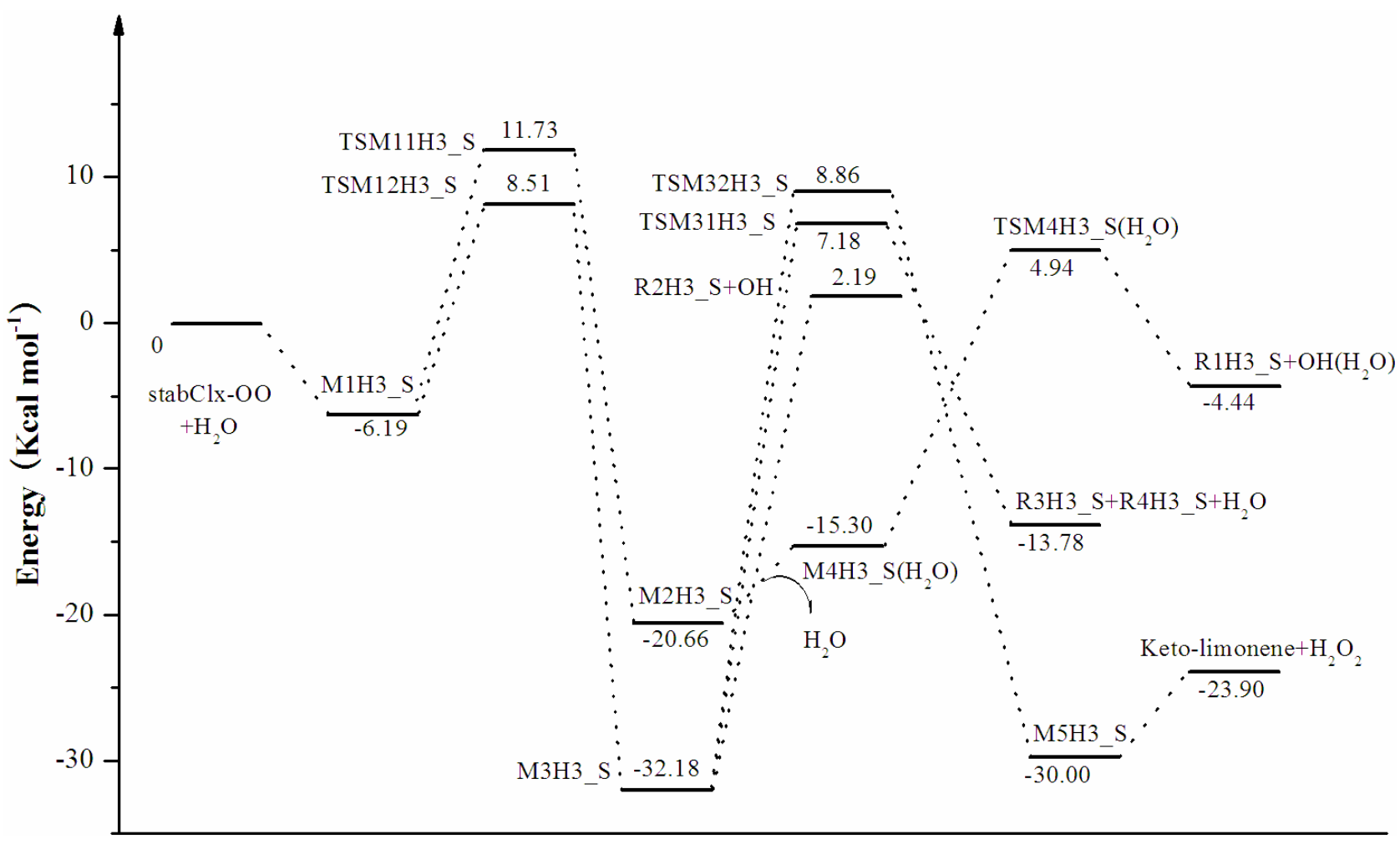

\section{Conclusions}

In the present study, several important aspects of the gas-phase reaction of the stabilized Criegee intermediates and $\mathrm{H}_{2} \mathrm{O}$ have been investigated.

The present study leads us to the following conclusions:

(a) The reaction between the stabilized Criegee intermediates (stabCI-OO, stabCI- $\mathrm{CH}_{3}-\mathrm{OO}$ and stabCI $x$-OO) and $\mathrm{H}_{2} \mathrm{O}$ is the three-step reaction. At the first stage, the formation of a hydrogen-bonded complex occurs. At the second stage, the reaction can proceed via the 
following two reaction pathways: (1) formation of $\mathrm{OH}$ radicals with water-catalyzed $\mathrm{H}$ migration; and (2) formation of $\alpha$-hydroxy hydroperoxide. The formation of $\alpha$-hydroxy hydroperoxide (reaction (2)), the reaction of stabCI-OO and $\mathrm{H}_{2} \mathrm{O}$ occurs via six different degradation pathways, while the reaction of stabCI- $\mathrm{CH}_{3}-\mathrm{OO}$ and stabCIx-OO with $\mathrm{H}_{2} \mathrm{O}$ occurs via three different reaction pathways.

(b) The formation of $\mathrm{OH}$ radicals with water-catalyzed $\mathrm{H}$ migration path (aH1_S, aH2_S and aH3_S) and formation of $\alpha$-hydroxy hydroperoxide (reaction pathways b1H1_S, b1H2_S and b1H3_S) may be considered as possible sources of $\mathrm{OH}$ radicals in the Earth's atmosphere. The formation of $\alpha$-hydroxy hydroperoxide (reaction pathways b6H1_S, b3H2_S and b3H3_S) can be considered as possible sources of atmospheric $\mathrm{H}_{2} \mathrm{O}_{2}$.

(c) The $\operatorname{CCSD}(\mathrm{T}) / 6-31 \mathrm{G}(\mathrm{d})+\mathrm{CF}$ activation energies are in the range of 14.70-21.98 kcal mol ${ }^{-1}$ with respect to corresponding hydrogen-bond complexes (M1H1_S, M1H2_S, M1H3_S) between stabilized Criegee intermediates and $\mathrm{H}_{2} \mathrm{O}$. The formation of $\alpha$-hydroxy hydroperoxide (reaction (2)) for the reaction of stabCIx-OO and $\mathrm{H}_{2} \mathrm{O}$ is the most favorable pathway with the activation energy of $14.70 \mathrm{kcal} \mathrm{mol}^{-1}$.

(d) For the reaction of stabCI-OO and $\mathrm{H}_{2} \mathrm{O}$, with the reaction between our optimized stabCI-OO (syn stabCI-OO) and water, the formation of $\mathrm{OH}$ radicals with water-catalyzed $\mathrm{H}$ migration path or reaction (1) is more favorable than the formation of $\alpha$-hydroxy hydroperoxide or reaction (2). This conclusion is opposite to that obtained in the previous theoretical study of the reaction between isoprene stabilized Criegee intermediates and $\mathrm{H}_{2} \mathrm{O}$ by Anglada. For the reaction of stabCI- $\mathrm{CH}_{3}-\mathrm{OO}$ and stabCI $x$-OO with $\mathrm{H}_{2} \mathrm{O}$, the formation of $\alpha$-hydroxy hydroperoxide (reaction (2)) is more favorable than the formation of $\mathrm{OH}$ radicals with water-catalyzed $\mathrm{H}$ migration path or reaction (1). This conclusion is consistent with results of the previous theoretical study of the reaction between isoprene stabilized Criegee intermediates and $\mathrm{H}_{2} \mathrm{O}$ by Anglada.

\section{Acknowledgments}

This work was financially supported by the Science Foundation of Chinese Research Academy of Environmental Sciences (Grant 2012-YSKY-15) and National Natural Science Foundation of China (No. 40975073). Additional support was provided by the CRAES Supercomputing Facilities.

\section{Conflict of Interest}

All the authors declare no conflict of interest.

\section{References}

1. Hatakeyama, S.; Akimoto, H. Reactions of Criegee intermediates in the gas phase. Res. Chem. Intermed. 1994, 20, 503-524.

2. Ryzhkov, A.B.; Ariya, P.A. A theoretical study of the reactions of carbonyl oxide with water in atmosphere: The role of water dimer. Chem. Phys. Lett. 2003, 367, 423-429.

3. Criegee, R. Mechanism of ozonolysis. Angew. Chem. Int. Ed. Engl. 1975, 14, 745-751. 
4. Neeb, P.; Horie, O.; Moortgat, G.K. The nature of the transitory product in the gas-phase ozonolysis of ethane. Chem. Phys. Lett. 1995, 246, 150-156.

5. Hatakeyama, S.; Bandow, H.; Okuda, M.; Akimoto, H. Reactions of peroxymethylene and methylene (1A1) with water in the gas phase. J. Phys .Chem. 1981, 85, 2249-2254.

6. Crehuet, R.; Anglada, J.M.; Bofill, J.M. Tropospheric formation of hydroxymethyl hydroperoxide, formic acid, $\mathrm{H}_{2} \mathrm{O}_{2}$, and $\mathrm{OH}$ from carbonyl oxide in the presence of water vapor: A theoretical study of the reaction mechanism. Chem. Eur. J. 2001, 7, 2227-2235.

7. Jenkin, M.E.; Saunders, S.M.; Pilling, M.J. The tropospheric degradation of volatile organic compounds: A protocol for mechanism development. Atmos. Environ. 1997, 31, 81-104.

8. Gäb, S.; Hellpointner, E.; Turner, W.V.; Korte, F. Hydroxymethyl hydroperoxide and bis(hydroxymethy1) peroxide from gas-phase ozonolysis of naturally occurring alkenes. Nature 1985, 316, 535-536.

9. Barnes, I.; Bastian, V.; Becker, K.H.; Zhu, T. Kinetics and products of the reactions of nitrate radical with monoalkenes, dialkenes, and monoterpenes. J. Phys.Chem. 1990, 94, 2413-2419.

10. Becke A D. Density-functional thermochemistry. III. The role of exact exchange. J. Phys .Chem. 1993, 98, 5648-5652.

11. Neeb, P.; Sauer, F.; Horie, O.; Moortgat, G.K. Formation of hydroxymethyl hydroperoxide and formic acid in alkene ozonolysis in the presence of water vapour. Atmos. Environ. 1997, 31, $1417-1423$.

12. Hasson, A.S.; Orzechowska, G.; Paulson, S.E. Production of stabilized Criegee intermediates and peroxides in the gas phase ozonolysis of alkenes 1. ethene, trans-2-butene, and 2,3-dimethyl-2butene. J. Geophys. Res. 2001, 106, 34131-34142.

13. Hasson, A.S.; Ho, A.W.; Kuwata, K.T.; Paulson, S.E. Production of stabilized Criegee intermediates and peroxides in the gas phase ozonolysis of alkenes 2 . asymmetric and biogenic alkenes. J. Geophys. Res. 2001, 106, 34143-34153.

14. Sauer, F.; Schafer, C.; Neeb, P.; Horie, O.; Moortgat, G.K. Formation of hydrogen peroxide in the ozonolysis of isoprene and simple alkenes under humid conditions. Atmos. Environ. 1999, 33, 229-241.

15. Hewitt, C.N.; Kok, G.L. Formation and occurrence of organic hydroperoxides in the troposphere: Laboratory and field observations. J. Atmos. Chem. 1991, 12, 181-194.

16. Simonaitis, R.; Olsyna, K.J.; Meagher, J.F. Production of hydrogen peroxide and organic peroxides in the gas phase reactions of ozone with natural alkenes. Geophys. Res. Lett. 1991, 18, 9-12.

17. Martinez, R.I.; Herron, J.T. Gas-phase reaction of $\mathrm{SO}_{2}$ with a Criegee intermediate in the presence of water vapor. J. Environ. Sci. Health A 1981, 16, 623-636.

18. Wolff, S.; Boddenberg, A.; Thamm, J.; Turner, W.V.; Gäb, S. Gas-phase ozonolysis of ethene in the presence of carbonyl-oxide scavengers. Atmos. Environ. 1997, 31, 2965-2969.

19. Winterhalter, R.; Neeb, P.; Grossmann, D.; Kolloff, A.; Horie, O.; Moortgat, G.K. Products and mechanism of the gas phase reaction of ozone with $\beta$-pinene. J. Atmos. Chem. 2000, 35, 165-197.

20. Puxbaum, H.; Rosenberg, C.; Gregori, M.; Lanzerstorfer, C.; Ober, E.; Winiwarter, W. Atmospheric concentrations of formic and acetic acid and related compounds in eastern and northern Austria. Atmos. Environ. 1988, 22, 2841-2850. 
21. Hellpointner, E.; Gäb, S. Detection of Methyl, Hydroxymethyl and hydroxyethyl hydroperoxides in air and precipitation. Nature 1989, 107, 631-634.

22. Grosjean, D. Organic acids in southern California air: Ambient concentrations, mobile source emissions, in situ formation and removal processes. Environ. Sci. Technol. 1989, 23, 1506-1514.

23. Sanhueza, E.; Santana, M.; Hermoso, M. Gas- and aqueous-phase formic and acetic acids at a tropical cloud forest site. Atmos. Environ. 1992, 26A, 1421-1426

24. Lawrence, J.E.; Koutrakis, P. Measurement of atmospheric formic and acetic acids: Methods evaluation and results from field studies. Environ. Sci. Technol. 1994, 28, 957-964.

25. Granby, K.; Christensen, C.S.; Lohse, C. Urban and semi-rural observations of carboxylic acids and carbonyls. Atmos. Environ. 1997, 31, 1403-1415.

26. Marklund, S. Mechanisms of the irreversible inactivation of horseradish peroxidase caused by hydroxymethyl hydroperoxide. Arch. Biochem. Biophys. 1973, 154, 614-622.

27. Möller, D. The possible role of $\mathrm{H}_{2} \mathrm{O}_{2}$ in new-type forest decline. Atmos. Environ. 1989, 23, $1625-1627$.

28. Hewitt, C.N.; Kok, G.L.; Fall, R. Hydroxyperoxides exposed to ozone mediate air pollution damage to alkene emitters. Nature 1990, 344, 56-58.

29. Calvert, J.G.; Lazrus, A.; Kok, G.L.; Heikes, B.G.; Walega, J.G.; Lind, J.; Cantrell, C.A. Chemical mechanisms of acid generation in the troposphere. Nature 1985, 317, 27-35.

30. Niki, H.; Maker, P.D.; Savage, C.M.; Breitenbach, L.P.; Hurley, M.D. FTIR spectroscopic study of the mechanism for the gas-phase reaction between ozone and tetramethylethylene. J. Phys. Chem. 1987, 91, 941-946.

31. Jonsson, Å.; Hallquist, M.; Ljungström, E. Influence of $\mathrm{OH}$ scavenger on the water effect on secondary organic aerosol formation from ozonolysisof limonene, $\Delta^{3}$-carene, and $\alpha$-pinene. Environ. Sci. Technol. 2008, 42, 5938-5944.

32. Leungsakul, S.; Jaoui, M.; Kamens, R.M. Kinetic Mechanism for predicting secondary organic aerosol formation from the reaction of D-limonene with ozone. Environ. Sci. Technol. 2005, 39, 9583-9594.

33. Dowideit, P.; von Sonntag, C. Reaction of ozone with ethene and its methyl- and chlorine-substituted derivatives in aqueous solution. Environ. Sci. Technol. 1998, 32, 1112-1119.

34. Anglada, J.M.; González, J.; Torrent-Sucarrat, M. Effects of the substituents on the reactivity of carbonyl oxides. A theoretical study on the reaction of substituted carbonyl oxides with water. Phys. Chem. Chem. Phys. 2011, 13, 13034-13045.

35. Aplincourt, P.; Ruiz-López, M.F. Theoretical study of formic acid anhydride formation from carbonyl oxide in the atmosphere. J. Phys. Chem. A 2000, 104, 380-388.

36. Anglada, J.M.; Aplincourt, P.; Bofill, J.M.; Cremer, D. Atmospheric formation of OH radicals and $\mathrm{H}_{2} \mathrm{O}_{2}$ from alkene ozonolysis under humid conditions. Chemphyschem 2002, 3, 215-221.

37. Aplincourt, P.; Anglada, J.M. Theoretical studies on isoprene ozonolysis under tropospheric conditions. 1. Reaction of substituted carbonyl oxides with water. J. Phys. Chem. A 2003, 107, 5798-5811.

38. Mebel, A.M.; Morokuma, K.; Lin, M.C. Modification of the Gaussian-2 theoretical model: The use of coupled cluster energies, densityfunctional geometries, and frequencies. J. Chem. Phys. 1995, 103, 7414-7421. 
39. Guenther, A.; Geron, C.; Pierce, T.; Lamb, B.; Harley, P.; Fall, R. Natural emissions of non-methane volatile organic compounds, carbon monoxide, and oxides of nitrogen from North America. Atmos. Environ. 2000, 34, 2205-2230.

40. Ramírez-Ramírez, V.M.; Nebot-Gil, I. Theoretical study of the $\mathrm{OH}$ addition to the endocyclic and exocyclic double bonds of the D-limonene. Chem. Phys. Lett. 2005, 409, 23-28.

41. Jiang, L.; Xu, Y.S.; Ding, A.Z. Reaction of stabilized Criegee intermediates from ozonolysis of limonene with sulfur dioxide: Ab initio and DFT study. 2010. J. Phys. Chem. A 2010, 114, 12452-12461.

42. Wang, Y.D. Theory Study on Mechanism of $\mathrm{O}_{3}$-Initiated Atmospheric Photooxidation of Terpenes. Master's Dissertation, Shandong University, Jinan, China, 2008.

43. Leungsakul, S.; Jeffries, H.E.; Kamens, R.M. A kinetic mechanism for predicting secondary aerosol formation from the reactions of D-limonene in the presence of oxides of nitrogen and natural sunlight. Atmos. Environ. 2005, 39, 7063-7082.

44. Neeb, P.; Horie, O.; Moortgat, G.K. The ethene-ozone reaction in the gas phase. J. Phys. Chem. A 1998, 102, 6778-6785.

45. Herron, J.T.; Huie, E. Stopped-flow studies of the mechanisms of ozone-alkene reactions in the gas phase. Ethylene. J. Am. Chem. Soc. 1977, 99, 5430-5435.

46. Martinez, R.I.; Herron, J.T. Stopped-flow studies of the mechanisms of ozone-alkene reactions in the gas phase: Trans-2-butene. J. Phys. Chem. 1988, 92, 4644-4648.

47. Gutbrod, R.; Kraka, E.; Schindler, R.N.; Cremer, D. Kinetic and theoretical investigation of the gas-phase ozonolysis of isoprene: Carbonyl oxides as an important source for $\mathrm{OH}$ radicals in the atmosphere. J. Am. Chem. Soc. 1997, 119, 7330-7342.

48. Anglada, J.M.; Bofill, J.M.; Olivella, S.; Sole, A. Theoretical investigation of the low-lying electronic states of dioxirane: Ring opening to dioxymethane and dissociation into $\mathrm{CO}_{2}$ and $\mathrm{H}_{2}$. J. Phys. Chem. A 1998, 102, 3398-3406.

49. Chen, B.Z.; Anglada, J.M.; Huang, M.B.; Kong, F. The reaction of $\mathrm{CH}_{2}\left(\mathrm{X}^{3} \mathrm{~B} 1\right)$ with $\mathrm{O}_{2}\left(\mathrm{X}^{3 \Sigma_{g}^{-}}\right)$: A theoretical CASSCF/CASPT2 investigation. J. Phys. Chem. A 2002, 106, 1877-1884.

50. Paulson, S.E.; Chung, M.Y.; Hasson, A.S. OH radical formation from the gas-phase reaction of ozone with terminal alkenes and the relationship between structure and mechanism. J. Phys. Chem. A 1999, 103, 8125-8138.

51. Aplincourt, P.; Ruiz-López, M.F. Theoretical investigation of reaction mechanisms for carboxylic acid formation in the atmosphere. J. Am. Chem. Soc. 2000, 122, 8990-8997.

52. Frisch, M.J.; Trucks, G.W.; Schlegel, H.B.; Scuseria, G.E.; Robb, M.A.; Cheeseman, J.R.; Montgomery, J.A., Jr.; Vreven, T.; Kudin, K.N.; Burant, J.C.; et al. Gaussian 03, Revision E.01; Gaussian, Inc.: Wallingford, CT, USA, 2004.

53. Hariharan, P.C.; Pople, J.A. The influence of polarization functions on molecular orbital hydrogenation energies. Theor. Chim. Acta 1973, 28, 213-222.

54. Gonzalez, C.; Schlegel, H.B. An improved algorithm for reaction path following. J. Chem. Phys. 1989, 90, 2154-2161.

55. Baptista, L.; Pfeifer, R.; da Silva, E.C.; Arbilla, G. Kinetics and thermodynamics of limonene ozonolysis. J. Phys. Chem. A 2011, 115, 10911-10919. 
56. Szabo, A.; Ostlund, N.S. Modern Quantum Chemistry: Introduction to Advanced Electronic Structure Theory; Macmillan: New York, NY, USA, 1986.

57. Lei, W.; Derecskei-Kovacs, A.; Zhang, R. Ab initio study of $\mathrm{OH}$ addition reaction to isoprene. J. Chem. Phys. 2000, 113, 5354-5360.

58. Suh, I.; Lei, W.; Zhang, R. Experimental and theoretical studies of isoprene reaction with $\mathrm{NO}_{3}$. J. Phys. Chem. A 2001, 105, 6471-6478.

59. Zhang, D.; Zhang, R. Mechanism of $\mathrm{OH}$ formation from ozonolysis of isoprene: A quantum-chemical study. J. Am. Chem. Soc. 2002, 124, 2692-2703.

60. Jiang, L.; Wang, W.; Xu, Y.S. Theoretical investigation of the $\mathrm{NO}_{3}$ radical addition to double bonds of limonene. Int. J. Mol. Sci. 2009, 10, 3743-3754.

61. Jiang, L.; Wang, W.; Xu, Y.S. Ab initio investigation of $\mathrm{O}_{3}$ addition to double bonds of limonene. Chem. Phys. 2010, 368, 108-112.

62. Gutbrod, R.; Schindler, R.N.; Kraka, E.; Cremer, D. Formation of OH radicals in the gas phase ozonolysis of alkenes: The unexpected role of carbonyl oxides. Chem. Phys. Lett. 1996, 252, 221-229.

63. Olzmann, M.; Kraka, E.; Cremer, D.; Gutbrod, R.; Andersson, S. Energetics, kinetics, and product distributions of the reactions of ozone with ethene and 2,3-dimethyl-2-butene. J. Phys. Chem. A 1997, 101, 9421-9429.

64. Cremer, D.; Kraka, E.; Szalay, P.G. Decomposition modes of dioxirane, methyldioxirane and dimethyldioxirane-A CCSD(T), MR-AQCC and DFT investigation. Chem. Phys. Lett. 1998, 292, 97-109.

65. Xu, F.; Wang, H.; Zhang, Q.Z.; Zhang, R.X.; Qu, X.H.; Wang, W.X. Kinetic properties for the complete series reactions of chlorophenols with $\mathrm{OH}$ radicals-Relevance for dioxin formation. Environ. Sci. Technol. 2010, 44, 1399-1404.

66. Sun, X.Y.; He, M.X.; Zhang, Q.Z.; Wang, W.X.; Jalbout, A.F. Quantum chemical study on the atmospheric photooxidation of Methyl Vinyl Ether (MVE). J. Mol. Struc. 2008, 868, 87-93.

67. Drozd, G.T.; Kroll, J.; Donahue, N.M. 2,3-Dimethyl-2-butene (TME) ozonolysis: Pressure dependence of stabilized criegee intermediates and evidence of stabilized vinyl hydroperoxides. J. Phys. Chem. A 2011, 115, 161-166.

68. Kurtén, T.; Donahue, N.M. MRCISD studies of the dissociation of vinylhydroperoxide, $\mathrm{CH}_{2} \mathrm{CHOOH}$ : There is a saddle point. J. Phys. Chem. A 2012, 116, 6823-6830.

(C) 2013 by the authors; licensee MDPI, Basel, Switzerland. This article is an open access article distributed under the terms and conditions of the Creative Commons Attribution license (http://creativecommons.org/licenses/by/3.0/). 